\title{
Simulation of trace gas redistribution by convective clouds - Liquid phase processes
}

\author{
Y. Yin, D. J. Parker, and K. S. Carslaw \\ School of the Environment, University of Leeds, Leeds, U.K. \\ Received 6 August 2001 - Published in Atmos. Chem. Phys. Discuss. 3 September 2001 \\ Revised 16 November 2001 - Accepted 20 November 2001 - Published 4 December 2001
}

\begin{abstract}
A two-dimensional dynamic cloud model with detailed microphysics and a spectral treatment of gas scavenging was used to simulate trace gas vertical redistribution in precipitating continental and maritime clouds. A general picture of gas transport in such clouds has been developed by examining the sensitivity to a range of parameters, including cloud dynamic and microphysical structure, gas solubility, and the method of calculating gas uptake by droplets. Gases with effective Henry's law constants $\left(H^{*}\right)$ ranging from zero to greater than $10^{9} \mathrm{~mol} \mathrm{dm}^{-3} \mathrm{~atm}^{-1}$ were simulated. The abundance of highly soluble gases in the uppermost parts (top $1 \mathrm{~km}$ or so) of continental precipitating clouds was found to be as much as $20-50 \%$ of that of the insoluble tracer under conditions where the mixing ratio of the tracer was approximately $5 \%$ of its boundary layer value. The abundance of highly soluble gases was approximately 6 times higher in the uppermost parts of the continental cloud than in the maritime cloud, due to differences in wet removal efficiency in the two cloud types. A fully kinetic calculation of gas uptake, as opposed to assuming Henry's law equilibrium, was found to have a significant effect on gas transport, with the abundance of highly soluble gases in the uppermost parts of the cloud being a factor of 5 lower in the equilibrium simulations. The temperature dependence of the Henry's law constant was also found to be an important parameter in determining the abundance of soluble gases at cloud top, with the abundance of moderately soluble gases being as much as $70 \%$ lower when the temperature dependence of $H^{*}$ was included. This reduction in abundance was found to be equivalent to increasing the temperature-independent solubility by a factor of 7 . The vertical transport of soluble gases could be parameterized in large-scale models by normalizing against the transport of tracers. However, our results suggest that there is no straightforward scaling factor, particularly if small concentrations of
\end{abstract}

Correspondence to: Y. Yin (yan@env.leeds.ac.uk) highly soluble gases in the upper troposphere need to be defined.

\section{Introduction}

Convective clouds play an important role in the vertical transport and wet removal of trace species that are emitted primarily at the Earth's surface or formed inside the planetary boundary layer. They allow within an hour or less an efficient vertical transport of gases and particles from the boundary layer to the upper troposphere.

The rapid vertical transport of air into the free and upper troposphere (UT) is important for two reasons: firstly, it can affect the chemistry of the UT region by transporting chemically reactive trace gases. Cloud transport may lead to a direct change in the abundance of trace gases in the UT region, or species abundances may be affected over longer periods of time through subsequent chemical reactions. Secondly, convective clouds may perturb the aerosol physical and chemical properties in the UT by acting as a direct source of aerosols from lower atmospheric layers or by providing a source of aerosol precursor gases, such as $\mathrm{SO}_{2}$ or dimethyl sulfide. Convective clouds may also transport chemical species that can subsequently partition into the UT aerosols, thereby affecting their chemical composition.

The importance of cloud transport of trace species has been shown by numerous authors for different clouds and cloud systems. Measurements dealing with the vertical transport of trace gases were carried out, e.g. by Ehhalt et al. (1985), Ching and Alkezweeny (1986), Drummond et al. (1988), and Pickering et al. (1989). Based on aircraft tracer observations, Ching and Alkezweeny (1986) suggested that mixed-layer pollutants can be lifted above the planetary boundary layer into the overlying free troposphere or cloud 
layer by non-precipitating but active or venting-type cumulus clouds.

Numerical models have been used to investigate the vertical transport of different trace gases by convective clouds. Using a two dimensional "Staubsauger" (vacuum cleaner) model, Chatfield and Crutzen (1984) studied the $\mathrm{SO}_{2}$ distribution in the tropical marine atmosphere, especially in relation to cloud transport, and their results suggested that a significant fraction of DMS can escape oxidation in the marine boundary layer and be transported to the upper troposphere by deep convection, especially in the intertropical convergence zone (ITCZ) region. Tremblay (1987) used a cumulus model to examine the transport of $\mathrm{HNO}_{3}, \mathrm{SO}_{2}$, $\mathrm{NH}_{3}$, and $\mathrm{H}_{2} \mathrm{O}_{2}$. Wang and Chang (1993) used a 3-D cloud resolving model to examine transport of $\mathrm{HNO}_{3}, \mathrm{SO}_{2}$, and $\mathrm{H}_{2} \mathrm{O}_{2}$. Flossmann and Wobrock (1996) and Kreidenweis et al. (1997) examined the transport of $\mathrm{SO}_{2}$ through convective clouds, including the effect of in-cloud chemical reactions. The transport of sulfur dioxide and dimethyl sulfide (DMS) into the free and upper troposphere is important because of the role played by these gases in aerosol formation. More recently, Mari et al. (2000) studied the transport of $\mathrm{CO}, \mathrm{CH}_{3} \mathrm{OOH}, \mathrm{CH}_{2} \mathrm{O}, \mathrm{H}_{2} \mathrm{O}_{2}, \mathrm{HNO}_{3}$, and $\mathrm{SO}_{2}$ in a 1-D entraining/detraining plume model with ice microphysics, and compared the results with observations from the TRACE-A (Trace and Atmospheric Chemistry Near the Equator-Atlantic) campaign. A comprehensive review of the observational and modeling studies on cloud venting by a wide variety of cloud types has been given by Cotton et al. (1995).

Crutzen and Lawrence (2000) used a global ChemistryTransport model (MATCH) to investigate the impact of convective and large-scale precipitation scavenging on the transport of trace gases from the earth's surface. Their results show, when only dissolution of species in the liquid phase is taken into account, mixing ratio reductions in the middle and upper troposphere of about $10 \%, 50 \%$, and $90 \%$ for gases with Henry's law constants of $10^{3}, 10^{4}$, and $10^{5} \mathrm{~mol} \mathrm{dm}^{-3}$ $\mathrm{atm}^{-1}$, respectively. However, this model does not resolve clouds.

Using a three-dimensional convective cloud model with a parameterization of mixed phase particle microphysics, Barth et al. (2001) investigated the fate of tracers of varying solubilities in a deep convective system over central USA. They find that the transport of gases to the UT depends strongly on gas solubility and the assumptions made about gas retention in ice particles.

The detailed cloud modelling studies outlined above have all focussed on transport of a limited number of gases under well defined conditions; often relevant to a specific set of observations. The gases have been selected to represent typical high, low, and moderate solubility gases or to compare model results with observations. Although there is a reasonably well defined group of gases whose transport to the UT is of particular importance to the chemistry of this region of the atmosphere, a complete understanding of the composition of the UT region, including its aerosol loading, requires a wider range of gases to be considered.

Organic species are one example of a group of gases whose solubility varies almost continuously from insoluble to extremely soluble. The sole source of primary organic species is the earth's surface. However, recent observations using an aerosol mass spectrometer indicate that UT aerosols often contain more organic material than sulfate (Murphy et al., 1998). Such observations confirm that our understanding of the influences on aerosol composition in the UT are far from complete. The composition of the aerosol organic matter is not known, but it is likely to be composed of a very wide range of water-soluble species from natural and anthropogenic sources. Candidate species for the organic components of atmospheric aerosols have been identified by Saxena and Hildemann (1996) based on estimated solubilities in water, mostly at $25^{\circ} \mathrm{C}$. However, the range of species of potential importance is likely to be much greater in the UT due to the lower temperatures and higher gas solubilities there. For example, the solubility of a typical short chain carboxylic acid with an enthalpy of solution of about $4 \times 10^{4} \mathrm{~J} \mathrm{~mol}^{-1}$ is approximately 400 times higher at $-50^{\circ} \mathrm{C}$ than it is at $25^{\circ} \mathrm{C}$. However, highly soluble species are also likely to be scavenged in the convective cloud column, thus reducing their abundance in the UT. Thus, a complete understanding of the factors that control UT aerosol composition requires a careful analysis of the transport of gases with wide ranging solubility.

The purpose of our study is to identify systematic changes in species transport depending on gas solubility, change in solubility with temperature, and cloud microphysical structure. We restrict the simulations to liquid phase processes, and concentrate on developing a picture of the factors that control gas transport in the absence of ice particles. In a further study we introduce ice particles and examine the effect that they have on gas transport for the same clouds. In contrast to previous studies, we do not restrict our simulations to specific gases under specific conditions. A moderate convective cloud is used with different background $\mathrm{CCN}$ spectra and different cloud morphology. Trace gases with effective Henry's law constant ranging from zero up to $10^{9} \mathrm{~mol} \mathrm{dm}^{-3}$ $\mathrm{atm}^{-1}$ are calculated.

A brief description of the model is given in Sect. 2, followed by the initial conditions for the simulations and design of the numerical experiments in Sect. 3. In Sect. 4, the main results are presented, and discussions and summaries are given in Sect. 5.

\section{Model description}

In this study we use a two-dimensional slab-symmetric nonhydrostatic cloud model (see Yin et al. (2000) for more details). The wind components in the horizontal and vertical 
Table 1. Equilibrium reactions of trace gas dissociation in water and the reaction constants (after Sander (1999) and Seinfeld and Pandis (1998)). The temperature-dependence of the equilibrium constant $K$ is expressed as $K=K_{298} \exp \left[-\frac{\Delta H}{R}\left(\frac{1}{T}-\frac{1}{298}\right)\right]$

\begin{tabular}{|c|c|c|c|}
\hline Equilibrium Reaction & $\begin{array}{c}K_{298} \\
{\left[\mathrm{~mol} \mathrm{dm}^{-3} \mathrm{~atm}^{-1}\right.} \\
\left.\text { or } \mathrm{mol} \mathrm{dm}^{-3}\right]\end{array}$ & $\frac{-\Delta H}{R}$ & Reference \\
\hline $\mathrm{HNO}_{3}(\mathrm{~g}) \rightleftharpoons \mathrm{HNO}_{3}(\mathrm{aq})$ & $2.1 \times 10^{5}$ & & Schwartz and White (1981) \\
\hline $\mathrm{HNO}_{3}(\mathrm{aq}) \rightleftharpoons \mathrm{NO}_{3}^{-}+\mathrm{H}^{+}$ & 15.4 & 8700 & Schwartz and White (1981) \\
\hline $\mathrm{HCl}(\mathrm{g}) \rightleftharpoons \mathrm{HCl}(\mathrm{aq})$ & 19. & 600 & Dean $(1992)$ \\
\hline $\mathrm{HCl}(\mathrm{aq}) \rightleftharpoons \mathrm{H}^{+}+\mathrm{Cl}^{-}$ & $1.74 \times 10^{6}$ & 6900 & Marsh and McElroy (1985) \\
\hline $\mathrm{H}_{2} \mathrm{O}_{2}(\mathrm{~g}) \rightleftharpoons \mathrm{H}_{2} \mathrm{O}_{2}(\mathrm{aq})$ & $8.3 \times 10^{4}$ & 7400 & O’Sullivan et al. (1996) \\
\hline $\mathrm{H}_{2} \mathrm{O}_{2}(\mathrm{aq}) \rightleftharpoons \mathrm{HO}_{2}^{-}+\mathrm{H}^{+}$ & $2.2 \times 10^{-12}$ & -3730 & Smith and Martell (1976) \\
\hline $\mathrm{HCOOH}(\mathrm{g}) \rightleftharpoons \mathrm{HCOOH}(\mathrm{aq})$ & $8.9 \times 10^{3}$ & 6100 & Johnson et al. (1996) \\
\hline $\mathrm{HCOOH}(\mathrm{aq}) \rightleftharpoons \mathrm{HCOO}^{-}+\mathrm{H}^{+}$ & $1.78 \times 10^{-4}$ & -20 & Martell and Smith (1977) \\
\hline $\mathrm{HO}_{2}(\mathrm{~g}) \rightleftharpoons \mathrm{HO}_{2}(\mathrm{aq})$ & $5.7 \times 10^{3}$ & & Régimbal and Mozurkewich (1997) \\
\hline $\mathrm{HO}_{2}(\mathrm{aq}) \rightleftharpoons \mathrm{H}^{+}+\mathrm{O}_{2}^{-}$ & $3.50 \times 10^{-5}$ & & Perrin $(1982)$ \\
\hline $\mathrm{HCHO}(\mathrm{g}) \rightleftharpoons \mathrm{HCHO}(\mathrm{aq})$ & 2.5 & 7200 & Betterton and Hoffmann (1988) \\
\hline $\mathrm{HCHO}(\mathrm{aq})+\mathrm{H}_{2} \mathrm{O} \rightleftharpoons \mathrm{H}_{2} \mathrm{C}(\mathrm{OH})_{2}(\mathrm{aq})$ & $2.53 \times 10^{3}$ & 4020 & Le Henaff (1968) \\
\hline $\mathrm{CH}_{3} \mathrm{C}(\mathrm{O}) \mathrm{OOH}(\mathrm{g}) \rightleftharpoons \mathrm{CH}_{3} \mathrm{C}(\mathrm{O}) \mathrm{OOH}(\mathrm{aq})$ & $8.4 \times 10^{2}$ & 5300 & O'Sullivan et al. (1996) \\
\hline $\mathrm{CH}_{3} \mathrm{OOH}(\mathrm{g}) \rightleftharpoons \mathrm{CH}_{3} \mathrm{OOH}(\mathrm{aq})$ & $3.1 \times 10^{2}$ & 5200 & O’Sullivan et al. (1996) \\
\hline $\mathrm{CH}_{3} \mathrm{OH}(\mathrm{g}) \rightleftharpoons \mathrm{CH}_{3} \mathrm{OH}(\mathrm{aq})$ & $2.2 \times 10^{2}$ & 4900 & Snider and Dawson (1985) \\
\hline $\mathrm{NH}_{3}(\mathrm{~g}) \rightleftharpoons \mathrm{NH}_{4} \mathrm{OH}$ & 61 & 4200 & Clegg and Brimblecombe (1989) \\
\hline $\mathrm{NH}_{4} \mathrm{OH} \rightleftharpoons \mathrm{NH}_{4}^{+}+\mathrm{OH}^{-}$ & $1.75 \times 10^{-5}$ & -450 & Smith and Martell (1976) \\
\hline $\mathrm{HNO}_{2}(\mathrm{~g}) \rightleftharpoons \mathrm{HNO}_{2}(\mathrm{aq})$ & 50. & 4900 & Becker et al. (1996) \\
\hline $\mathrm{HNO}_{2}(\mathrm{aq}) \rightleftharpoons \mathrm{NO}_{2}^{-}+\mathrm{H}^{+}$ & $5.1 \times 10^{-4}$ & -1260 & Schwartz and White (1981) \\
\hline $\mathrm{OH}(\mathrm{g}) \rightleftharpoons \mathrm{OH}(\mathrm{aq})$ & 25 & 5280 & Klaning et al. (1985) \\
\hline $\mathrm{CH}_{3} \mathrm{O}_{2}(\mathrm{~g}) \rightleftharpoons \mathrm{CH}_{3} \mathrm{O}_{2}(\mathrm{aq})$ & 6.0 & 5600 & Jacob (1986) \\
\hline $\mathrm{CH}_{3} \mathrm{C}(\mathrm{O}) \mathrm{O}_{2} \mathrm{NO}_{2}(\mathrm{~g}) \rightleftharpoons \mathrm{CH}_{3} \mathrm{C}(\mathrm{O}) \mathrm{O}_{2} \mathrm{NO}_{2}(\mathrm{aq})$ & 2.8 & 6500 & Kames et al. (1991) \\
\hline $\mathrm{NO}_{3}(\mathrm{~g}) \rightleftharpoons \mathrm{NO}_{3}(\mathrm{aq})$ & 2.0 & 2000 & Thomas et al. (1998) \\
\hline $\mathrm{SO}_{2}(\mathrm{~g}) \rightleftharpoons \mathrm{SO}_{2} \cdot \mathrm{H}_{2} \mathrm{O}$ & 1.4 & 3120 & Lide et al. (1995) \\
\hline $\mathrm{SO}_{2} \cdot \mathrm{H}_{2} \mathrm{O} \rightleftharpoons \mathrm{HSO}_{3}^{-}+\mathrm{H}^{+}$ & $1.23 \times 10^{-2}$ & 1960 & Smith and Martell (1976) \\
\hline $\mathrm{HSO}_{3}^{-} \rightleftharpoons \mathrm{SO}_{3}^{2-}+\mathrm{H}^{+}$ & $6.61 \times 10^{-8}$ & 1500 & Smith and Martell (1976) \\
\hline $\mathrm{CO}_{2}(\mathrm{~g}) \rightleftharpoons \mathrm{CO}_{2} \cdot \mathrm{H}_{2} \mathrm{O}$ & $3.40 \times 10^{-2}$ & 2420 & Smith and Martell (1976) \\
\hline $\mathrm{CO}_{2} \cdot \mathrm{H}_{2} \mathrm{O} \rightleftharpoons \mathrm{HCO}_{3}^{-}+\mathrm{H}^{+}$ & $4.46 \times 10^{-7}$ & -1000 & Smith and Martell (1976) \\
\hline $\mathrm{HCO}_{3}^{-} \rightleftharpoons \mathrm{CO}_{3}^{2-}+\mathrm{H}^{+}$ & $4.68 \times 10^{-11}$ & -1760 & Smith and Martell (1976) \\
\hline $\mathrm{O}_{3}(\mathrm{~g}) \rightleftharpoons \mathrm{O}_{3}(\mathrm{aq})$ & $1.1 \times 10^{-2}$ & 2400 & Hoffmann and Calvert (1985) \\
\hline $\mathrm{NO}_{2}(\mathrm{~g}) \rightleftharpoons \mathrm{NO}_{2}(\mathrm{aq})$ & $1.00 \times 10^{-2}$ & 2500 & Schwartz and White (1981) \\
\hline $\mathrm{NO}(\mathrm{g}) \rightleftharpoons \mathrm{NO}(\mathrm{aq})$ & $1.9 \times 10^{-3}$ & 1400 & Lide et al. (1995) \\
\hline
\end{tabular}

directions are calculated based on the vorticity equation and stream function. The dynamic equations are also solved for the virtual potential temperature perturbation $\left(\theta_{v}^{\prime}\right)$, the specific humidity perturbation $\left(q_{v}^{\prime}\right)$, the specific concentration of aerosols, and the number and mass concentrations of cloud particles in a spectral bin.

The microphysical processes included are: nucleation of aerosol particles, condensation and evaporation, collisioncoalescence, binary break-up (Low and List kernel), and sedimentation. All these microphysical processes are formulated and solved using the method of Multi-Moments (Tzivion et al., 1987).

The cloud particles are divided into 34 bins with mass doubling for adjacent bins $\left(m_{k+1}=2 m_{k}, k=1,2, \cdots, 34\right)$. The masses of the lower boundary of the first bin and the upper boundary of the last bin were $0.1598 \times 10^{-13}$ and $0.17468 \times 10^{-3} \mathrm{~kg}$, respectively, which correspond to drop diameters of 3.125 and $8063 \mu \mathrm{m}$. The aerosol spectrum is divided into 67 bins with a minimum radius of $0.0041 \mu \mathrm{m}$.

The grid size of the model is set to $300 \mathrm{~m}$ in both horizontal and vertical directions. The width and height of the domain are 30 and $12 \mathrm{~km}$, respectively. A time step of $2.5 \mathrm{~s}$ is used for diffusive growth/evaporation, $0.1 \mathrm{~s}$ for gas absorption, and $5 \mathrm{~s}$ for all other processes.

In order to keep the simulated cloud within the domain and at the same time to minimize the computer memory requirement, a moving coordinate system has been used for clouds formed under an environmental wind field.

To simulate the evolution of trace gases in the air and in cloud drops, the dynamic and microphysical equations are 
Table 2. Values of $N_{0}$ and $k$ in Eq. 11 used in simulations of the continental and maritime clouds

\begin{tabular}{lccc}
\hline Case & Supersaturation $[\%]$ & $N_{0},\left[\mathrm{~cm}^{-3}\right]$ & $k$ \\
\hline \multirow{3}{*}{ Continental } & $S \geq 0.4$ & 1000 & 0.5 \\
& $0.007 \leq S<0.4$ & 3990 & 2 \\
& $S<0.007$ & $6.62 \times 10^{7}$ & 4 \\
& & & \\
Maritime & $S>0.059$ & 100 & 0.7 \\
& $0.0015 \leq S \leq 0.059$ & 3990 & 2 \\
& $S<0.0015$ & $6.62 \times 10^{7}$ & 3.5 \\
\hline
\end{tabular}

also applied to the mixing ratio of a gas species $i$ in the air, $M_{a, i}$, and that in aqueous (droplet) phase, $M_{d, i}$. These equations are given as

$\frac{\partial M_{a, i}}{\partial t}=F_{q}\left(M_{a, i}\right)-D\left(M_{a, i}\right)-\left(\frac{\partial M_{a, i}}{\partial t}\right)_{\text {trans }}$

and

$$
\begin{aligned}
\frac{\partial M_{d, i, k}}{\partial t} & =F_{q}\left(M_{d, i, k}\right)-D\left(M_{d, i, k}\right) \\
& +S_{\text {trans }}+S_{\text {cond/evap }} \\
& +S_{\text {coll } / \text { break }}+S_{\text {sedim }}
\end{aligned}
$$

where the subscript $k$ denotes the drop spectral bin number. The terms $D$ and $F_{q}$ represent the advective and turbulent transfer operators. Entrainment appears as a result of subgrid turbulent mixing at the edges of the cloud (see Yin et al. (2000) for more details). The variation of these functions with spatial location is implied. Also, the $S$ terms represent sources/sinks of chemical species and mass transfer in a given bin due to microphysical processes, and are given by

$S=\left(\frac{\partial M_{d, i, k}}{\partial t}\right)$

with the subscripts standing for:

trans. mass transport of trace species between the gas and aqueous phase;

cond/evap. bin shift due to condensation and evaporation of water from drops;

coll/break. mass transfer of dissolved gas due to collisioncoalescence and break-up of drops;

sedim. transfer to lower layers and possible eventual loss of dissolved gases by sedimentation of drops.

2.1 Kinetics of mass transport between the gas and aqueous phase

The rate of mass transport between gas species $i$ and a group of aqueous drops with radius of $r$ and number concentration of $N_{r}$ (per mole of air), can be written as (e.g. Pandis and Seinfeld, 1989; Chen, 1992)

$\frac{d M_{d, i, r}}{d t}=\frac{3 \eta D_{g, i} N_{S h, i}}{R T r^{2}}\left(V_{r} N_{r} P_{i}-\frac{M_{d, i, r}}{H_{i}^{*}}\right)$,

where $M_{d, i, r}$ is the molar mixing ratio respect to air of gas species $i$ inside drops with radius $r, H^{*}$ the effective Henry's law constant of species $i, R$ the universal gas constant, $T$ the temperature, $D_{g, i}$ the diffusivity of gas species $i$ in air, $V_{r}$ the volume of drops with radius $r, P_{i}$ the partial pressure of gas species $i$ in the environment, $N_{S h, i}$ the mass ventilation coefficient (Sherwood number), and $\eta$ a factor to account for the free-molecular effect on mass transfer rate (Jacob, 1986), which is a function of the Knudsen number $K n$ and the sticking coefficient $\alpha_{i}$ of gas species $i$ to a spherical drop (Seinfeld and Pandis, 1998):

$\eta=\left\{1+\left[\frac{1.33+0.71 K n^{-1}}{1+K n^{-1}}+\frac{4\left(1-\alpha_{i}\right)}{3 \alpha_{i}}\right] K n\right\}^{-1}$.

The sticking coefficient $\alpha_{i}$ for gaseous species on small droplets has been an elusive quantity. In the measurements of the sticking coefficients of $\mathrm{SO}_{2}$ (Gardner et al., 1987) and $\mathrm{HO}_{2}$ (Mozurkewich et al., 1987) onto aqueous solutions, it has been found that the corresponding values of $\alpha_{i}$ are slightly larger than 0.01. Wang and Crutzen (1995) indicated that under typical natural atmospheric conditions the uptake of trace gases into cloud or rain droplets depends only weakly on the values of sticking coefficient because of the limitations on diffusive transfer. Based on previous studies (e.g. Pandis and Seinfeld, 1989; Wang and Crutzen, 1995) a value of 0.1 has been used in our simulation for all the species.

The effective Henry's law coefficient, $H^{*}$, for a species $i$ that undergoes aqueous phase dissociation differs from the Henry's law coefficient $H_{i}$ for the molecule, as it accounts for the ionic forms of the dissolved gas (e.g. Seinfeld and Pandis, 1998). For example, for a gas with two stages of dissociation, such as $\mathrm{SO}_{2}$,

$H_{i}^{*}=H_{i}\left[1+\frac{K_{1}}{\left[H^{+}\right]}+\frac{K_{1} K_{2}}{\left[H^{+}\right]^{2}}\right]$

where $K_{1}$ and $K_{2}$ are the first and second ionic dissociation coefficients.

Because the dissolved gases do not normally contribute to the drop size, Eq. (4) is a linear differential equation of order one and can be solved analytically as

$M_{d, i, \bar{r}_{k}}(\tau+\Delta \tau)=A(\tau)+\left[M_{d, i, \bar{r}_{k}}(\tau)-A(\tau)\right] \exp (B \Delta \tau),(7)$

where $\tau$ is the time step for gas dissolution, and

$A(\tau)=\frac{4}{3} \pi \bar{r}_{k}^{3} N_{k} P_{i}(\tau) H_{i}^{*}, \quad B=-\frac{3 D_{g, i} N_{S h, i} \eta}{\bar{r}_{k}^{2} R T H_{i}^{*}} ;$

$\bar{r}_{k}$ is the average radius of drops in a bin $k$, and is calculated as

$\bar{r}_{k}=\left[\frac{3}{4 \pi \rho_{w}} \frac{M_{k}}{N_{k}}\right]^{\frac{1}{3}}$, 
Table 3. List of simulations conducted in this study. More detailed explanations are given in Sect. 3.2

\begin{tabular}{lclll}
\hline Descriptor in text & Wind shear & CCN & Gas uptake & $H^{*}$ \\
\hline continental-unsheared & no & continental & kinetic & T-independent \\
continental-sheared & yes & continental & kinetic & T-independent \\
maritime-sheared & yes & maritime & kinetic & T-independent \\
continental-equilibrium & yes & continental & equilibrium & T-independent \\
continental-real & yes & continental & kinetic & T-dependent \\
maritime-real & yes & maritime & kinetic & T-dependent \\
\hline
\end{tabular}

Table 4. Ratio of the values in Fig. 12 (equilibrium) to those in Fig. 6 (non-equilibrium) at various altitude (in km) for gases with different effective Henry's law constant $H^{*}$ (in mol dm ${ }^{-3} \mathrm{~atm}^{-1}$ )

\begin{tabular}{lcccccc}
\hline Altitude[km] & $H^{*}=10^{2}$ & $H^{*}=10^{3}$ & $H^{*}=10^{4}$ & $H^{*}=10^{5}$ & $H^{*}=10^{6}$ & $H^{*}=10^{7}$ \\
\hline 0.0 & 1.0 & 1.0 & 0.92 & 0.75 & 0.69 & 0.66 \\
1.5 & 1.0 & 1.0 & 0.98 & 0.87 & 0.77 & 0.66 \\
3.0 & 1.0 & 1.0 & 0.99 & 0.87 & 0.76 & 0.67 \\
4.5 & 1.0 & 1.0 & 1.0 & 0.85 & 0.74 & 0.54 \\
6.0 & 1.0 & 1.0 & 0.99 & 0.92 & 0.78 & 0.52 \\
7.5 & 1.0 & 1.0 & 1.0 & 1.0 & 0.86 & 0.38 \\
\hline
\end{tabular}

where, $N_{k}$ and $M_{k}$ are the first and second moment of the drop spectral bin $k$.

\subsection{Gas solubilities}

The gas solubilities (Henry's law coefficients) and dissociation coefficients considered in this study are listed in Table 1. The temperature dependence of Henry's law coefficients and dissociation coefficients are expressed according to the van't Hoff's relation

$K(T)=K\left(T_{0}\right) \exp \left[\frac{-\Delta H}{R}\left(\frac{1}{T}-\frac{1}{T_{0}}\right)\right]$,

where $\Delta H$ is the enthalpy change for the equilibrium relations involved, $K\left(T_{0}\right)$ is the equilibrium constant at a standard temperature $T_{0}\left(T_{0}=298 \mathrm{~K}\right.$ in this study), and $R$ is the universal gas constant. The droplet $p \mathrm{H}$ is set to 5.0 for all size classes. The gases are treated as non-interacting; that is, no irreversible chemical reactions are included and the $p \mathrm{H}$ of the droplet doesn't change with the dissolution of acid gases. This simplistic approach is in accord with our desire to explore a full range of gas solubilities, rather than the specific properties of a few gases.

\section{Initial conditions and numerical experiments}

\subsection{Initial conditions}

Simulations were performed for maritime and continental situations. For both cases an artificial thermodynamic profile representative of typical conditions was used. The profile produces a cloud with a base at $8-10^{\circ} \mathrm{C}(1.5-1.8 \mathrm{~km})$ and a top between -25 and $-28^{\circ} \mathrm{C}(7.5-8.0 \mathrm{~km})$. Clouds in the real atmosphere are unlikely to remain free of ice particles above $-10^{\circ} \mathrm{C}$ level. However, our aim is to use these simulations as a baseline for understanding the more complex gas-particle interactions that occur in clouds containing ice. In order to initiate the cloud, a warm bubble of $600 \mathrm{~m}$ height and $600 \mathrm{~m}$ width, and temperature of $2^{\circ} \mathrm{C}$ higher than its surroundings was applied for one time step at $t=0$ in the middle of the domain.

The number concentration of aerosols large enough to act as cloud condensation nuclei $(\mathrm{CCN})$ distinguishes the maritime and continental clouds. The $\mathrm{CCN}$ number concentration in the model is expressed as a function of the supersaturation according to

$N(S)=N_{0}\left(S / S_{0}\right)^{k}$.

Here $N(S)$ is the cumulative number of $\mathrm{CCN}$ active at or below the supersaturation $S, S_{0}$ is the reference supersaturation $(1 \%)$ at which the cumulative concentration equals $N_{0}$, and $k$ an empirical parameter. In this paper the values of $N_{0}$ and $k$ representing a continental and a maritime cloud are determined based on Cooper et al. (1997), and Twomey and Wojciechowski (1969), respectively. The values of $N_{0}$ and $k$ for each $\mathrm{CCN}$ spectrum are given in Table 2 . In addition, the $\mathrm{CCN}$ are assumed to be composed of ammonium sulfate, regardless of size, and the $\mathrm{CCN}$ concentrations are assumed 
Table 5. Varying of the integrated species mass (mol) with enthalpy (above $4 \mathrm{~km}$ (or in the main outflow region) for moderately soluble gases. The effective Henry's law constant $H^{*}$ is given in mol dm ${ }^{-3}$ $\mathrm{atm}^{-1}$

\begin{tabular}{lcccc}
\hline$-\frac{\Delta H}{R}[\mathrm{~K}]$ & $H^{*}=10^{3}$ & $H^{*}=10^{4}$ & $H^{*}=10^{5}$ & $H^{*}=10^{6}$ \\
\hline 5000 & 104.15 & 59.58 & 23.56 & 14.52 \\
4000 & 105.90 & 64.29 & 24.85 & 14.62 \\
3000 & 107.29 & 69.12 & 26.41 & 14.77 \\
2000 & 108.37 & 73.88 & 28.28 & 14.96 \\
1000 & 109.18 & 78.45 & 30.52 & 15.23 \\
0 & 109.94 & 82.68 & 33.14 & 15.59 \\
\hline
\end{tabular}

Table 6. Varying of the integrated species mass (mol) with enthalpy at $7500 \mathrm{~m}$ level for moderately soluble gases. The effective Henry's law constant $H^{*}$ is given in mol dm $\mathrm{dm}^{-3}$

\begin{tabular}{lcccc}
\hline$-\frac{\Delta H}{R}[\mathrm{~K}]$ & $H^{*}=10^{3}$ & $H^{*}=10^{4}$ & $H^{*}=10^{5}$ & $H^{*}=10^{6}$ \\
\hline 5000 & 1.39 & 0.85 & 0.49 & 0.36 \\
4000 & 1.43 & 0.92 & 0.51 & 0.36 \\
3000 & 1.46 & 0.99 & 0.53 & 0.36 \\
2000 & 1.49 & 1.06 & 0.56 & 0.36 \\
1000 & 1.51 & 1.13 & 0.60 & 0.37 \\
0 & 1.52 & 1.20 & 0.63 & 0.38 \\
\hline
\end{tabular}

to decrease exponentially with altitude with a scale height of $2.5 \mathrm{~km}$ (according to Pruppacher and Klett (1997)).

The initial horizontal wind speed is set to $2 \mathrm{~m} \mathrm{~s}^{-1}$ at the surface level, linearly increasing to $10.7 \mathrm{~m} \mathrm{~s}^{-1}$ at about $9 \mathrm{~km}$, and constant at $10.7 \mathrm{~m} \mathrm{~s}^{-1}$ at higher levels. Simulations are also performed with zero horizontal wind.

The initial profiles of temperature, dew point temperature, wind speed, and CCN spectra are shown in Fig. 1.

Because the main purpose of these simulations is to estimate to what extent the gases from the boundary layer can be transported to the free atmosphere and upper troposphere, the initial trace gas mixing ratio was arbitrarily assumed to be $1 \mathrm{ppbv}$ and to be homogeneously distributed in the boundary layer with a height of $1.5 \mathrm{~km}$. Further simulations were performed to examine the relative contribution of entrained trace gases at different altitudes to the the budget in the UT.

\subsection{Numerical experiments}

Six numerical experiments were conducted to test the sensitivity of gas transport to gas solubility, cloud dynamics, and the initial conditions. The different simulations are listed in Table 3 and are now briefly described.

Gases with different solubilities were considered by varying the effective Henry's law constant $H^{*}$ from 0 (insoluble tracers) to $10^{9} \mathrm{~mol} \mathrm{dm}^{-3} \mathrm{~atm}^{-1}$ (highly soluble gases). The changes of $H^{*}$ with temperature were not considered in these baseline simulations. Further experiments with real gases, taking into account the change of solubility with temperature, provide a useful indication of the sensitivity of gas transport to this parameter. The equilibrium reactions and Henry's law constants of these gases are listed in Table 1.

Experiments were performed for continental clouds with and without horizontal wind shear. These experiments were designed to understand the sensitivity of gas transport to cloud dynamic structure. All subsequent simulations included wind shear. The continental cloud was compared with a maritime cloud by using a different CCN spectrum (see Sect. 3.1) in order to understand the sensitivity of gas transport to two very different cloud microphysical structures under the same environmental conditions. In the fourth simulation, gas uptake by drops was calculated based on Henry's law equilibrium, thus neglecting the time-dependent gas uptake into droplets. This sensitivity case was used to understand the influence of the equilibrium assumption on gas redistribution. Finally, the calculations were repeated using 20 real gases in the continental and maritime clouds. In these runs we include the temperature-dependence of solubility.

\section{Results}

4.1 General features of the cloud macro- and microstructure

The time-evolution of the maximum values of updraft speed, liquid water content (LWC), drop number concentration, rainfall rate, and rain amount at the surface in the continentalunsheared, continental-sheared, and maritime-sheared runs is shown in Fig. 2. In the continental-unsheared run, the cloud began to form after $13 \mathrm{~min}$ of simulation, and reached its maximum updraft $\left(18.5 \mathrm{~m} \mathrm{~s}^{-1}\right) 13$ min later. The peak values of droplet number concentration $\left(844 \mathrm{~cm}^{-3}\right)$ and liquid water content $\left(5.8 \mathrm{~g} \mathrm{~kg}^{-1}\right)$ were reached after 26 and $28 \mathrm{~min}$, respectively, or 13 and $15 \mathrm{~min}$ after cloud initiation. Rainfall started at $37 \mathrm{~min}$ and reached a maximum rate $\left(84 \mathrm{~mm} \mathrm{~h}^{-1}\right)$ at $47 \mathrm{~min}$. The maximum accumulated precipitation amount at the surface in this case was $14 \mathrm{~mm}$.

The clouds in the continental-sheared and maritimesheared cases appeared 2-3 min later than in the continentalunsheared case, although the same temperature and humidity profiles were used. The peak values of updraft speed were also smaller in the sheared runs. These results indicate that the background wind field used here postpones and prohibits cloud development, which is consistent with previous studies (e.g. Takeda, 1971). Accordingly, the clouds in the sheared cases also reached their peak values of updraft velocity, LWC, and droplet number concentration later than in the unsheared case.

The maximum droplet concentration reached only $119 \mathrm{~cm}^{-3}$ in the maritime simulation compared with $922 \mathrm{~cm}^{-3}$ in the continental run. The higher droplet concen- 

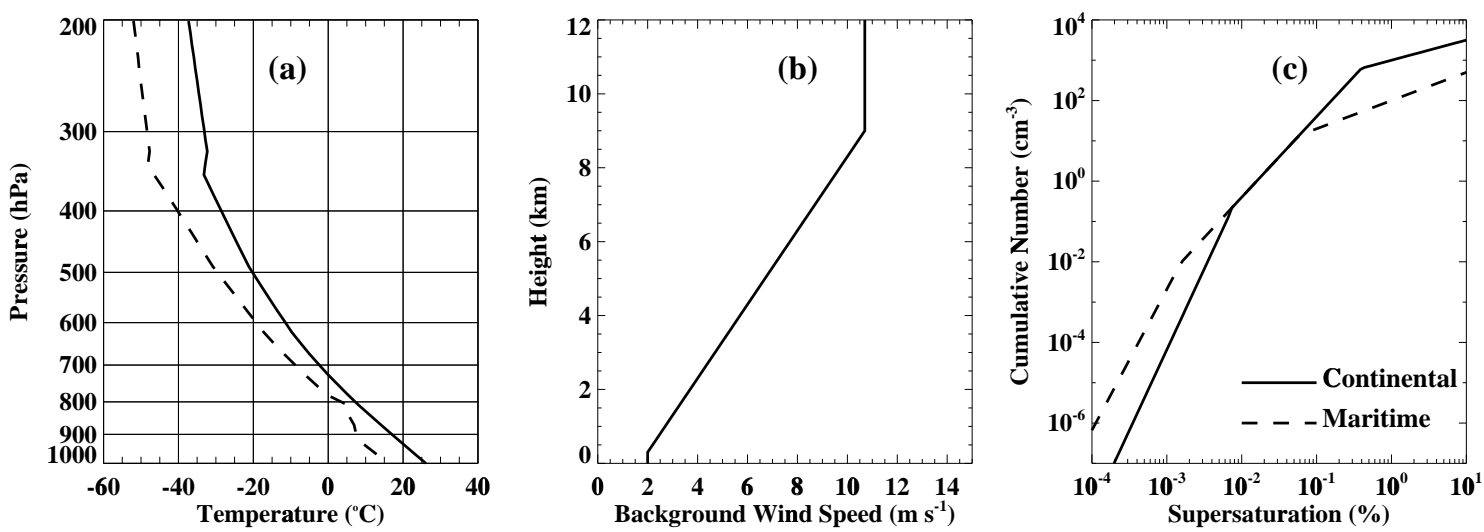

Fig. 1. (a) Initial profiles of temperature (solid line) and dew point temperature (dashed line), (b) background horizontal wind speed, and (c) CCN spectra used in the present work.

tration in the continental simulation leads to smaller cloud droplets and a reduced rainfall efficiency, which results from a reduced collision-coalescence efficiency. Consequently, both the rainfall rate and rain amount at the surface in the continental-sheared run were much lower than in the maritime-sheared run. In addition, the times for rain initiation and maximum rainfall rate were also 3-4 min later in the former case than in the latter. Such variations in rainfall rate can have an important influence on the efficiency of gas transport to the free and upper troposphere.

\subsection{General features of gas redistribution and the effect of cloud dynamics}

The continental-unsheared and sheared simulations have been designed to investigate the effect of cloud dynamic structure on the vertical redistribution of trace gases.

Figures 3, 4 and 5 show the spatial distributions of species within the continental clouds assuming an insoluble tracer and two soluble gases. The species abundances are expressed as a fraction of the initial boundary layer mixing ratio. The three gas solubilities represent an insoluble tracer $\left(H^{*}=0\right.$, Fig. 3), a moderately soluble gas $\left(H^{*}=10^{4} \mathrm{~mol} \mathrm{dm}^{-3} \mathrm{~atm}^{-1}\right.$, Fig. 4), and a highly soluble gas $\left(H^{*}=10^{7} \mathrm{~mol} \mathrm{dm}^{-3} \mathrm{~atm}^{-1}\right.$, Fig. 5).

In these simulations the insoluble tracer mixing ratio reaches a maximum of approximately $40 \%$ of its boundary layer value in the middle of the unsheared cloud $(\sim 5 \mathrm{~km}$ altitude) after $60 \mathrm{~min}$ (left side of Fig. 3). This transport is in good agreement with the simulations of Kreidenweis et al. (1997) (their Fig. 6). In contrast, the maximum concentration in the sheared cloud is only $25 \%$ of the boundary layer value. The reduced transport of the insoluble tracer in the sheared case results from the less vigorous and shorter-lived updraft, as shown in Fig. 2a.

The abundances of the soluble species are reduced relative to the insoluble tracer due to partitioning into cloud water fol- lowed by rain-out (compare Figs. 3e and 4c). After 60 min, the maximum concentration of the moderately soluble gas in the cloud is $25 \%$ of the boundary layer value, compared with $40 \%$ for the insoluble tracer. Although the maximum rainfall amount in the unsheared case is about twice as high as in the sheared case (Fig. 2e), the total abundance of the moderately soluble gas in the unsheared cloud is still higher, due to the more efficient dynamical transport in this case.

The abundance of the highly soluble gas (Fig. 5) is reduced to less than $5 \%$ of its boundary layer mixing ratio in the middle of the cloud after 60 min of simulation. A comparison of the gas-phase fraction with the total fraction in Fig. 5 also indicates that most of the highly soluble gas in the midtroposphere is in liquid phase. This fraction of gases will take part in further chemical reactions or be released when the cloud drops are completely evaporated.

A comparison of the different simulations shows that while the abundance of soluble gases is reduced significantly in the middle of the cloud (where concentrations are highest), the abundances of all gases are rather similar on the edge of the visible cloud (marked by the dotted lines). Thus, general statements about reduced transport of soluble gases are difficult to make; account must be taken for the very different transport properties to different parts of the cloud.

Figure 6 shows vertical profiles of the species abundances (gas + aqueous phase) in the continental clouds, normalized to the abundance of the insoluble tracer, which is shown on the left side of the figure. The abundance is expressed as the total gas amount (moles) at each level after $60 \mathrm{~min}$ of simulation once rainfall has ceased. Normalization of the gas abundance to that of the insoluble tracer highlights the relatively efficient transport of even highly soluble species to the top of the cloud. Although the total amount of the insoluble tracer transported to the top of the cloud is low (typically $\sim 5 \%$ of the boundary layer mixing ratio), Fig. 6 shows that the abundance of the highly soluble species is $\sim 50 \%$ of that of the insoluble tracer in the case of the unsheared cloud and 

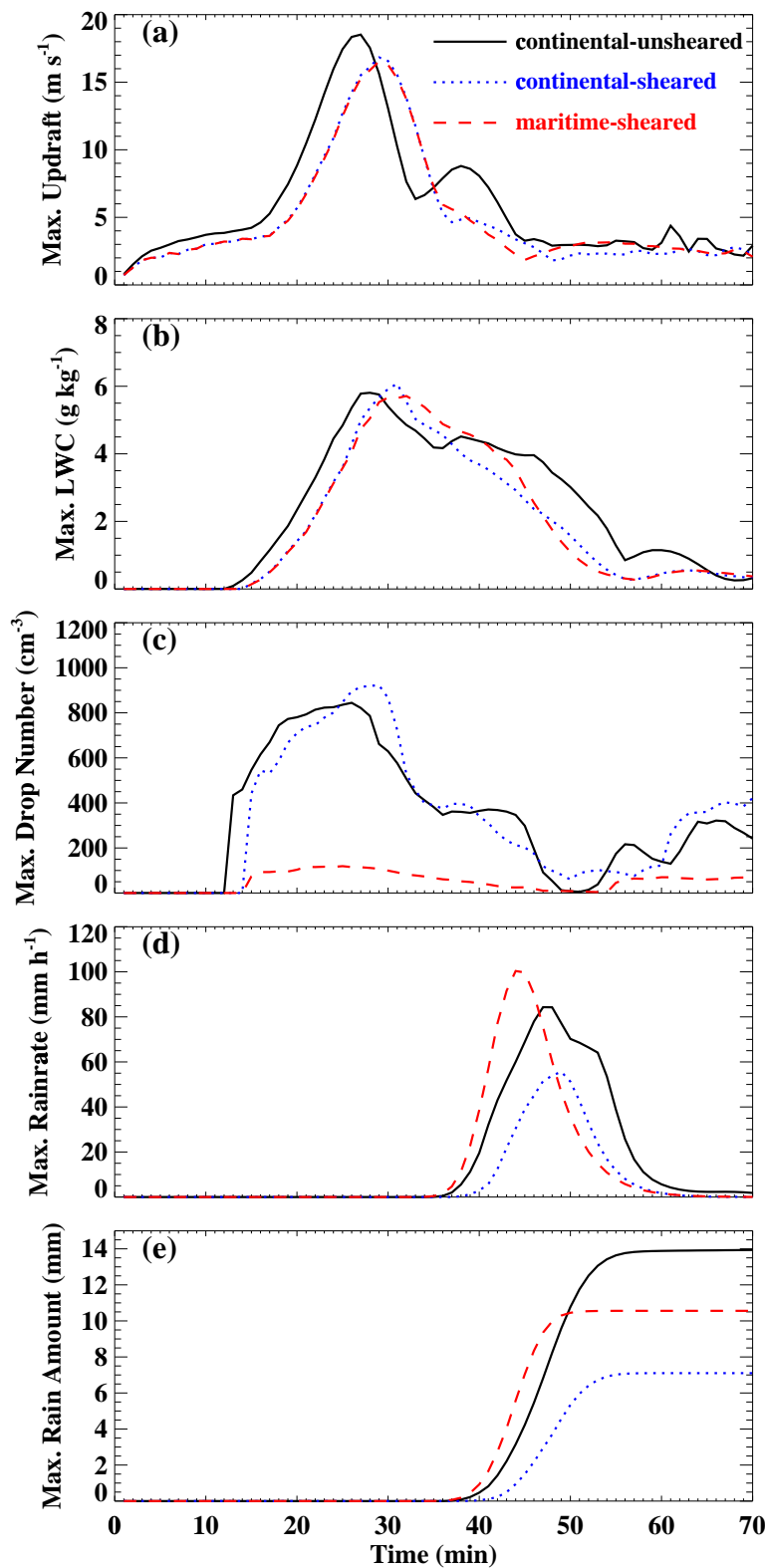

Fig. 2. Time-evolution of the maximum values of (a) updraft speed, (b) liquid water content (LWC), (c) number concentration of drops, (d) rainfall rate, and (e) accumulated rain amount on the ground in the continental-unsheared, continental-sheared, and maritimesheared simulations.

$20 \%$ for the sheared cloud. Calculated fractions more than 1 $\mathrm{km}$ outside the visible cloud are probably not reliable due to the extremely low concentrations involved.

The dependence of gas transport efficiency on gas solubility is shown in Fig. 7. It is seen from both the integrated species mass above $4 \mathrm{~km}$ (or in the main outflow region) and that near the cloud top layer that insoluble gases stand out as those with a solubility $H^{*}<10^{3} \mathrm{~mol} \mathrm{dm}^{-3} \mathrm{~atm}^{-1}$ and all such gases behave in an identical way in the cloud, and that highly soluble gases can be classed as those with $H^{*}$ $>10^{6} \mathrm{~mol} \mathrm{dm}^{-3} \mathrm{~atm}^{-1}$, and their behaviour in the cloud is also independent of the precise value of their solubility. The transport of moderately soluble gases $\left(10^{3}<\left(H^{*} / \mathrm{mol} \mathrm{dm}^{-3}\right.\right.$ $\left.\mathrm{atm}^{-1}\right)<10^{6}$ ) is highly dependent on the precise value of their solubility.

\subsection{The effect of cloud microphysical structure}

Figure 8 shows the vertical profile of the species abundances in the maritime-sheared cloud simulation. The main differences between the continental (Fig. 6) and maritime results are:

(1) The mass of highly soluble gases in the cloud top layer is significantly higher in the continental cloud than in the maritime cloud. For example, the highly soluble gas abundance at cloud top in the maritime cloud is approximately $3 \%$ of that of the insoluble tracer, while it is $20 \%$ in the continental cloud.

The strongly reduced abundance of soluble gases at the top of maritime clouds is related to the cloud microphysical structure. The relatively high efficiency for rain formation via collision-coalescence in the maritime case leads to the dissolved gas being removed out the cloud more efficiently. In addition, rainfall starts earlier in the maritime cloud and lasts longer than in the continental sheared cloud (Fig. 2d), both of which act to remove more soluble gases in the maritime cloud column.

(2) The differences between these two cases become less significant at lower levels. The lower mass at the $3000 \mathrm{~m}$ layer in the maritime-sheared simulation compared to that in continental sheared simulation is related to the stronger wet as well as dry deposition in this case, resulting from the heavier rainfall.

\subsection{The effect of assuming gas-liquid equilibrium}

We now examine the importance of explicit time-dependent calculations of gas transfer to droplets, rather than the alternative (and computationally faster) assumption that all droplets are in Henry's law equilibrium with the trace gases.

The two cases compared are the continental-sheared simulation, presented above, and a continental-equilibrium simulation, which also uses the sheared cloud dynamics. The gas dissolution process in the continental-sheared run is calculated using the kinetic equation Eq. 4, while the continental-equilibrium simulation calculates gas partitioning into droplets of all sizes based on thermodynamic equilibrium (Henry's law) between the gas phase and dissolved concentrations. The latter is also a common assumption in global chemical transport models.

Figures 9-11 show dissolved gas concentrations as a function of droplet size for gases with Henry's law constants of $10^{2}, 10^{4}$, and $10^{6} \mathrm{~mol} \mathrm{dm}^{-3} \mathrm{~atm}^{-1}$. The concentration of the low solubility gas in the droplets is identical in the two runs, 

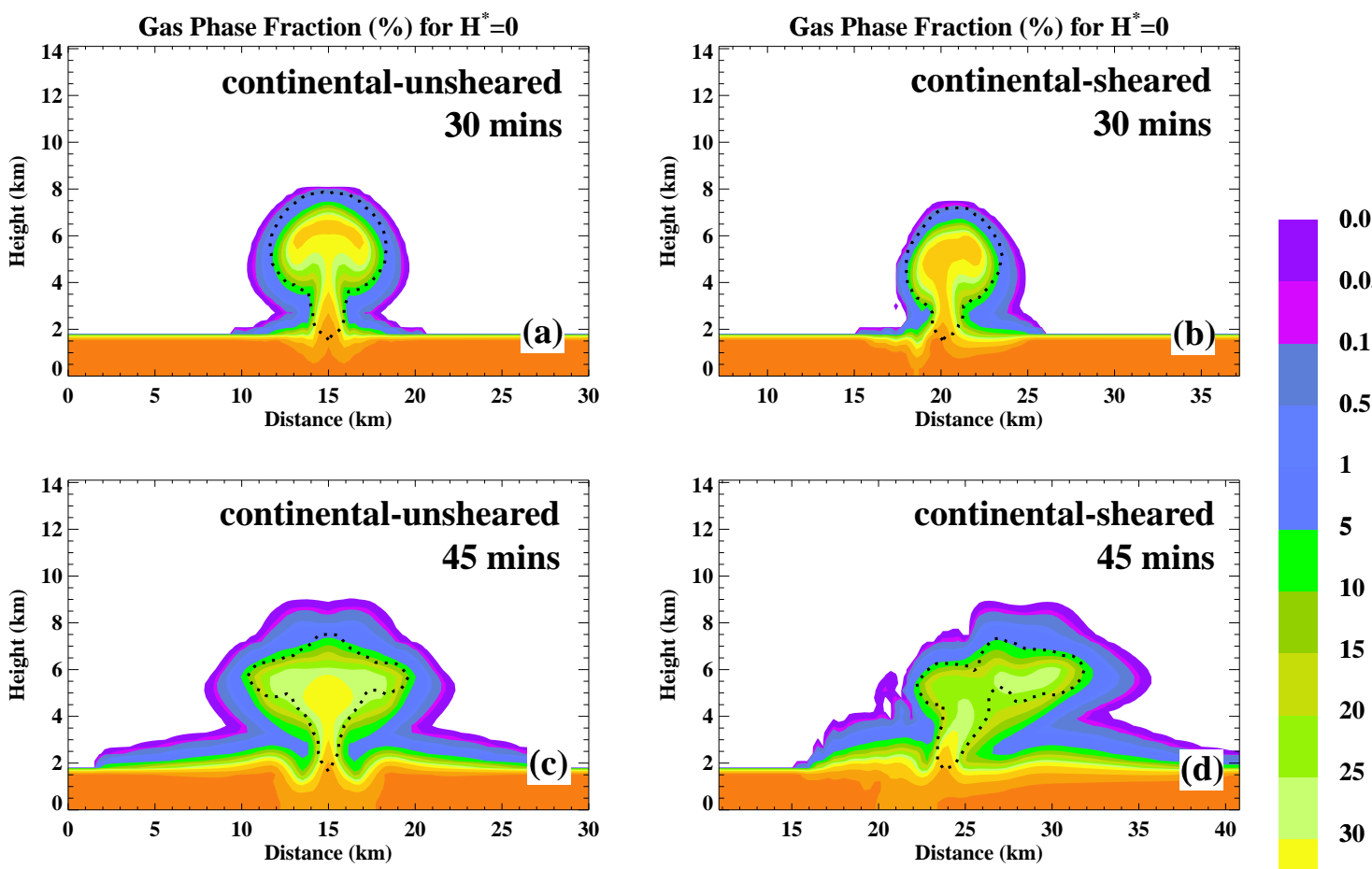

1
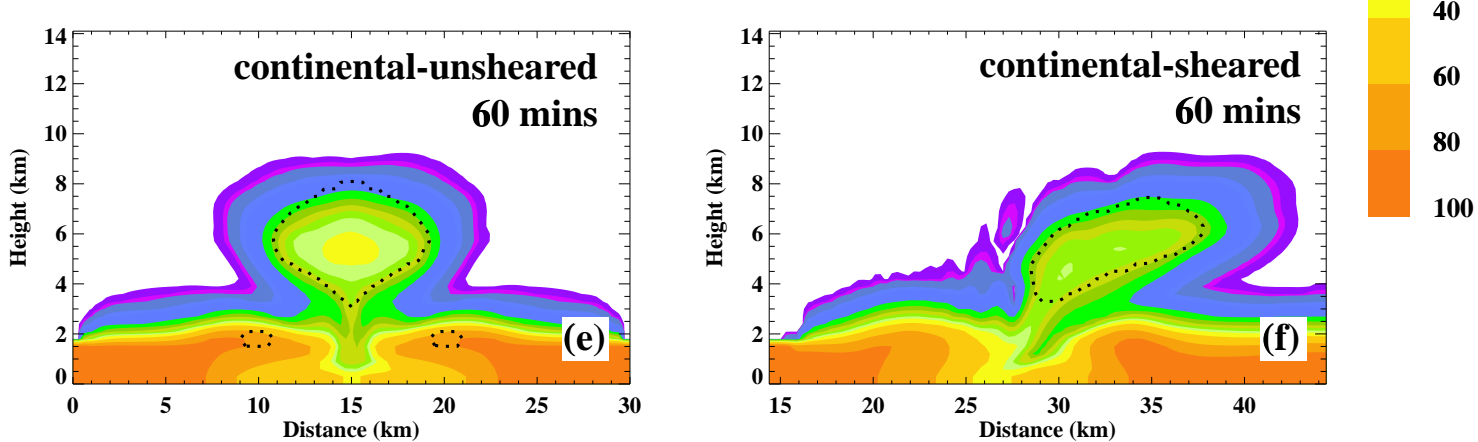

Fig. 3. Spatial distributions of the mixing ratio of an insoluble tracer as a fraction (percent) of the initial boundary layer value for (a) continental-unsheared case at $30 \mathrm{~min}$, (b) continental-sheared case at $30 \mathrm{~min}$, (c) continental-unsheared case at $45 \mathrm{~min}$, (d) continentalsheared case at $45 \mathrm{~min}$, (e) continental-unsheared case at $60 \mathrm{~min}$, and (f) continental-sheared case at $60 \mathrm{~min}$. The area within the black dotted line indicates visible cloud $\left(q_{c}>10^{-3} \mathrm{~g} \mathrm{~kg}^{-1}\right)$.

irrespective of droplet size (Fig. 9). In contrast, for gases with effective Henry's law constant of about $H^{*}=10^{4} \mathrm{~mol}$ $\mathrm{dm}^{-3} \mathrm{~atm}^{-1}$ (Fig. 10) only the cloud droplets in the region $1 \mathrm{~km}$ above the cloud base $(1.5-1.8 \mathrm{~km})$ reached equilibrium, while the relatively large cloud and rain drops at the lower part of the cloud and below cloud base were not in equilibrium. Furthermore, for high solubility gases (Fig. 11) the gas concentrations in most of the drops are far from equilibrium.

The results indicate that species with a solubility less than $\sim 10^{3} \mathrm{~mol} \mathrm{dm}^{-3} \mathrm{~atm}^{-1}$ can be assumed to be in Henry's law equilibrium, while tracers with a solubility between $10^{3}$ and $10^{5} \mathrm{~mol} \mathrm{dm}^{-3} \mathrm{~atm}^{-1}$ are in Henry's law equilibrium only for cloud droplets but not for rain drops. Species with even higher solubilities are not in Henry's law equilibrium at all.
Similar results were also reported by Barth et al. (2001) in simulation of a deep convective system over central USA.

One of the consequences of assuming Henry's law equilibrium for soluble gases in rain water can be seen by comparing the concentrations of dissolved gas in rain drops during the evolution of cloud and precipitation. It can be seen from Figs. 10 and 11 that the concentrations at $40 \mathrm{~min}$ calculated using the kinetic equation are less than those obtained by assuming equilibrium, but at $60 \mathrm{~min}$ the results are opposite, indicating that the equilibrium assumption could lead to overestimation of scavenging of soluble gases by rain drops.

The effect of the equilibrium assumption can be seen clearly in Fig. 12, which shows a vertical profile of soluble gas abundances normalized to the insoluble tracer. The 

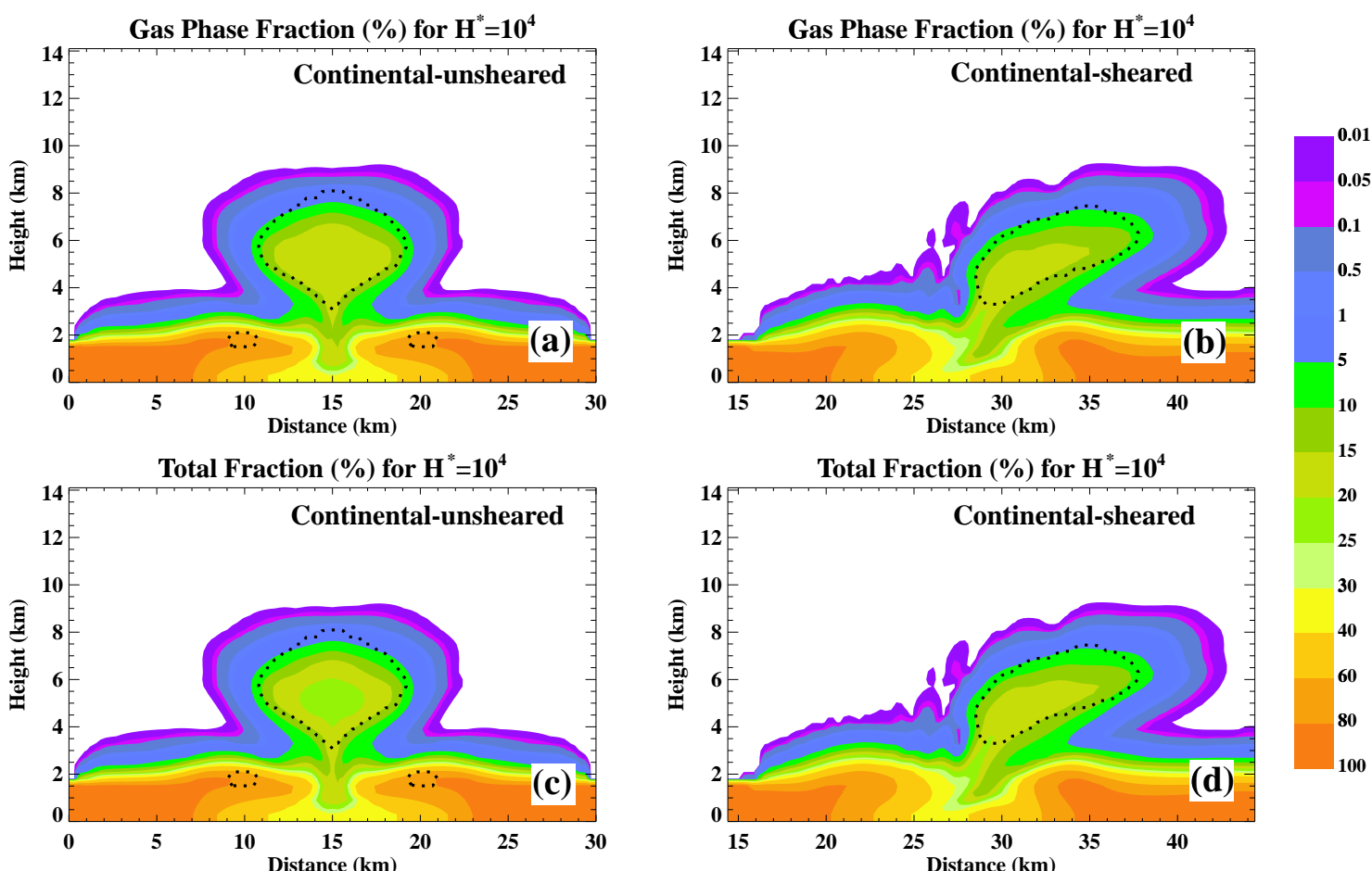

Fig. 4. Spatial distributions after $60 \mathrm{~min}$ of simulation of the mixing ratio of a moderately soluble gas $\left(H^{*}=10^{4} \mathrm{~mol} \mathrm{dm}^{-3}\right.$ atm $\left.{ }^{-1}\right)$ as a fraction (percent) of the initial boundary layer value for (a) the gas-phase abundance in the continental-unsheared case, (b) the gas-phase abundance in the continental-sheared case, (c) the total abundance (gas-phase plus liquid-phase) in the continental-unsheared case, and (d) the total abundance in the continental-sheared case. The area within the black dotted line indicates visible cloud $\left(q_{c}>10^{-3} \mathrm{~g} \mathrm{~kg}^{-1}\right)$.
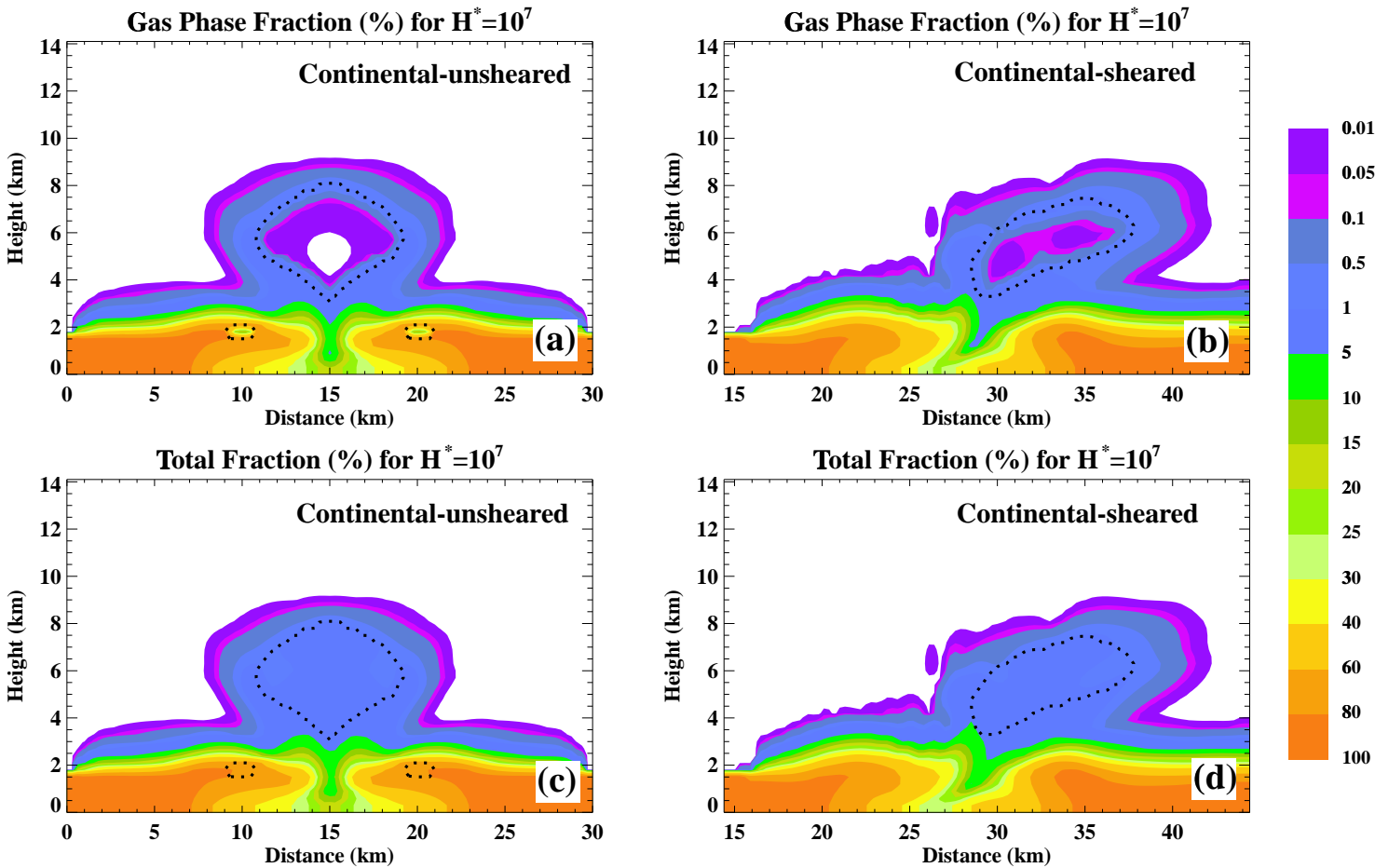

Fig. 5. Similar to Fig. 4, but for a highly soluble gas $\left(H^{*}=10^{7} \mathrm{~mol} \mathrm{dm}^{-3} \mathrm{~atm}^{-1}\right)$. 

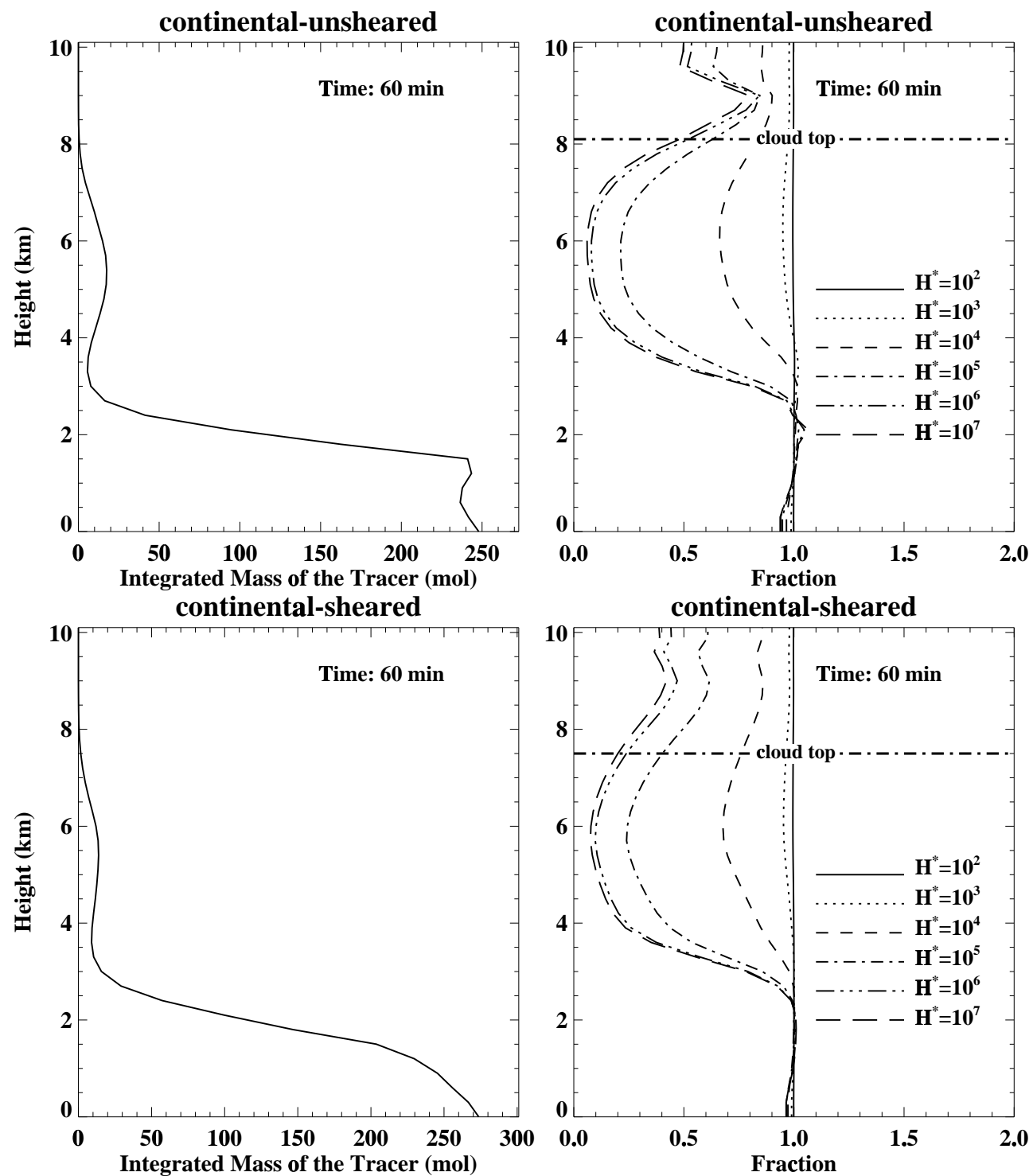

Fig. 6. Vertical profiles of the integrated species mass (gas phase + dissolved, in moles) of the insoluble tracer (left panels) and the abundance of soluble gases normalized to that of the insoluble tracer (right panels) for the continental-unsheared (top panels) and the continental-sheared (bottom panels) clouds after 60 min of simulation. The cloud top $\left(q_{c}>10^{-3} \mathrm{~g} \mathrm{~kg}^{-1}\right)$ is also indicated.

ratios of the values in this figure to those in Fig. 6 for the continental-sheared case are listed in Table 4. The total gas abundance below $3 \mathrm{~km}$ is significantly lower in the equilibrium simulation, especially for higher solubility gases, in spite of the fact that the dynamic and microphysical structure of the clouds formed in these two cases were the same. For example, the abundance of the most soluble gas $\left(H^{*}\right.$ $=10^{7} \mathrm{~mol} \mathrm{dm}^{-3} \mathrm{~atm}^{-1}$ ) is reduced by $34 \%$.

The effects of assuming equilibrium are also important in the upper parts of the cloud, which we are most interested in here. For $H^{*}=10^{6} \mathrm{~mol} \mathrm{dm}^{-3} \mathrm{~atm}^{-1}$ the abundance at cloud top is reduced from $25 \%$ of the tracer mixing ratio to $20 \%$. However, for the most soluble gas, the abundance at cloud top is reduced from $20 \%$ of the tracer mixing ratio to less than $8 \%$. Thus, the assumption of equilibrium, while easy to implement in a model, may significantly underestimate the transport of highly soluble gases to the upper parts of clouds.

It is interesting to compare the results of Crutzen and Lawrence (2000) (using a global model) with the 3-D cloud model results of Barth et al. (2001) and the 2-D cloud model results in this study for continental conditions. In the global model runs of Crutzen and Lawrence, the soluble gas abundances in the UT were about $80-90 \%$ and $10-20 \%$ of the insoluble tracer for $H^{*}=10^{3}$ and $10^{5} \mathrm{~mol} \mathrm{dm}^{-3} \mathrm{~atm}^{-1}$, respectively. In the Barth et al. study, the abundances of soluble tracers with $H^{*}=10^{3}$ and $10^{5} \mathrm{~mol} \mathrm{dm}^{-3} \mathrm{~atm}^{-1}$ were 

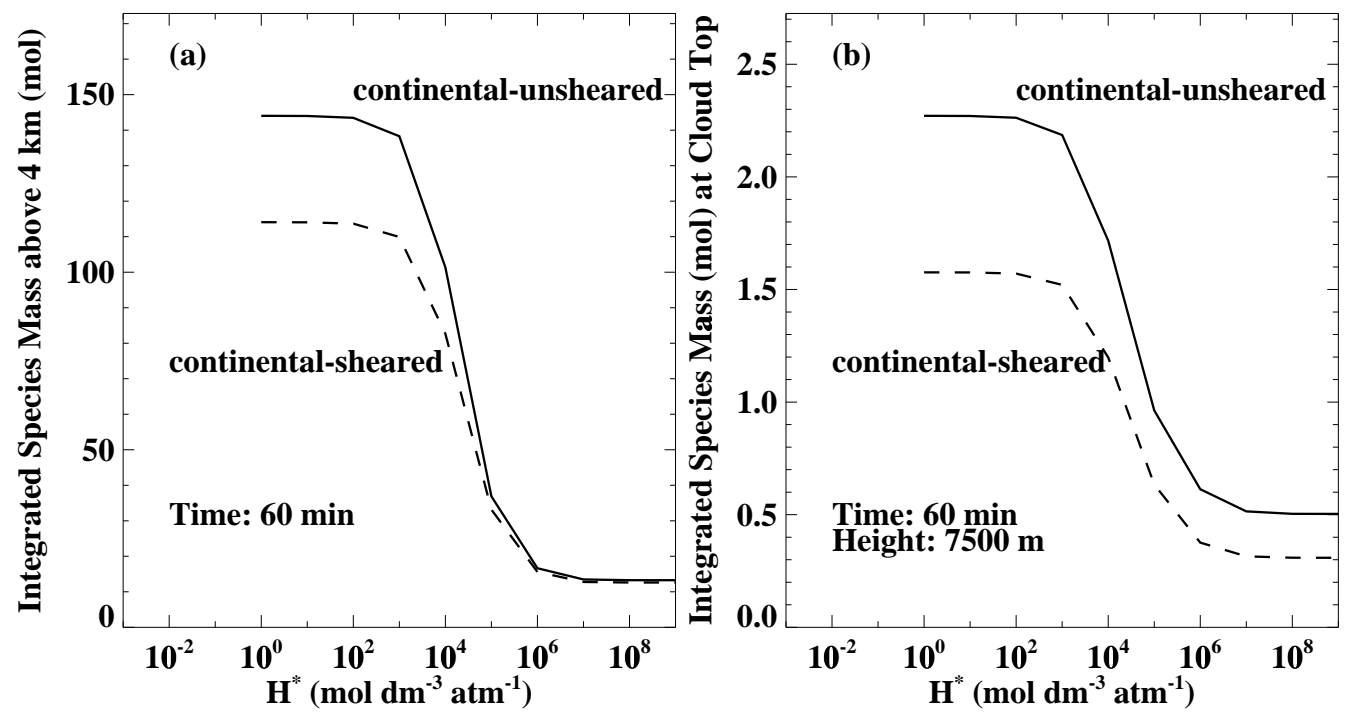

Fig. 7. A comparison of the integrated species abundance (in moles) (a) above $4 \mathrm{~km}$ (or in the outflow region), (b) $7500 \mathrm{~m}$ altitude (or near cloud top), as a function of effective Henry's law constant for the continental-unsheared cloud (solid line) and the continental-sheared cloud (dashed line) after $60 \mathrm{~min}$ of simulation. The width of the cloud in the $y$ direction was normalized to $1 \mathrm{~km}$ to calculate the integrated gas mass).
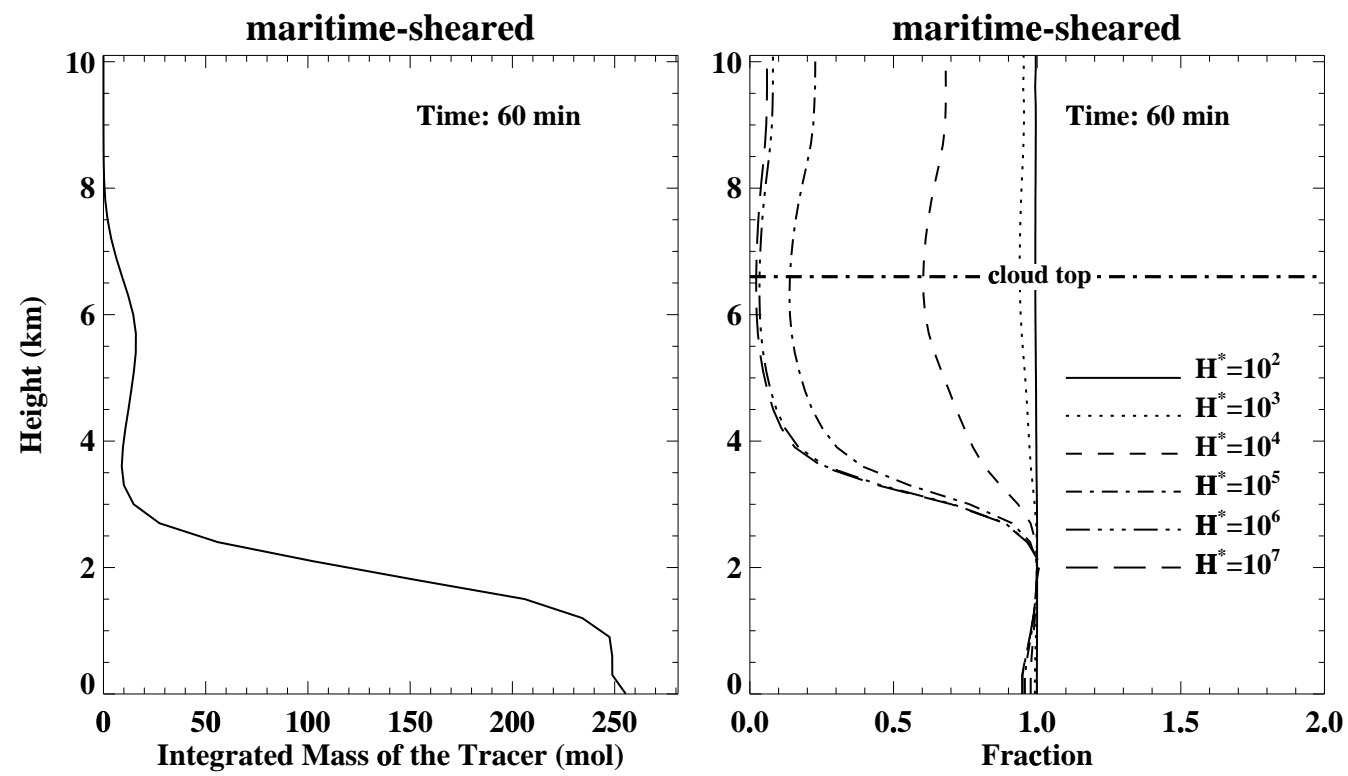

Fig. 8. (a) Vertical profile of the integrated total abundance (in moles) of the insoluble tracer in the maritime-sheared simulation; (b) the abundance of soluble gases normalized to the abundance of the tracer.

$95 \%$ and $40-60 \%$ of the insoluble tracer in the outflow region of the cloud. In our study, the soluble gas abundances in the outflow region (above $4 \mathrm{~km}$ altitude) are 90-95\% and 20$30 \%$ for $H^{*}=10^{3}$ and $10^{5} \mathrm{~mol} \mathrm{dm}^{-3}$ atm $^{-1}$, respectively. Thus, the cloud models produce higher abundances of soluble gases in the UT than does the global model of Crutzen and Lawrance (2000). Barth et al. attributed the difference between their results and those of Crutzen and Lawrence to the size-dependence of the averaging region and parameter- ization of the microphysical processes in their study, and a possible overestimate of the loss of highly soluble species in the upper troposphere by larger-scale models. The results obtained here support their last point. However, it should also be noted that the results reported here and by Barth et al. were obtained under specific thermodynamic conditions. The clouds and precipitations produced under such conditions were different from those reported by Crutzen and Lawrence for monthly mean values. The differences in 

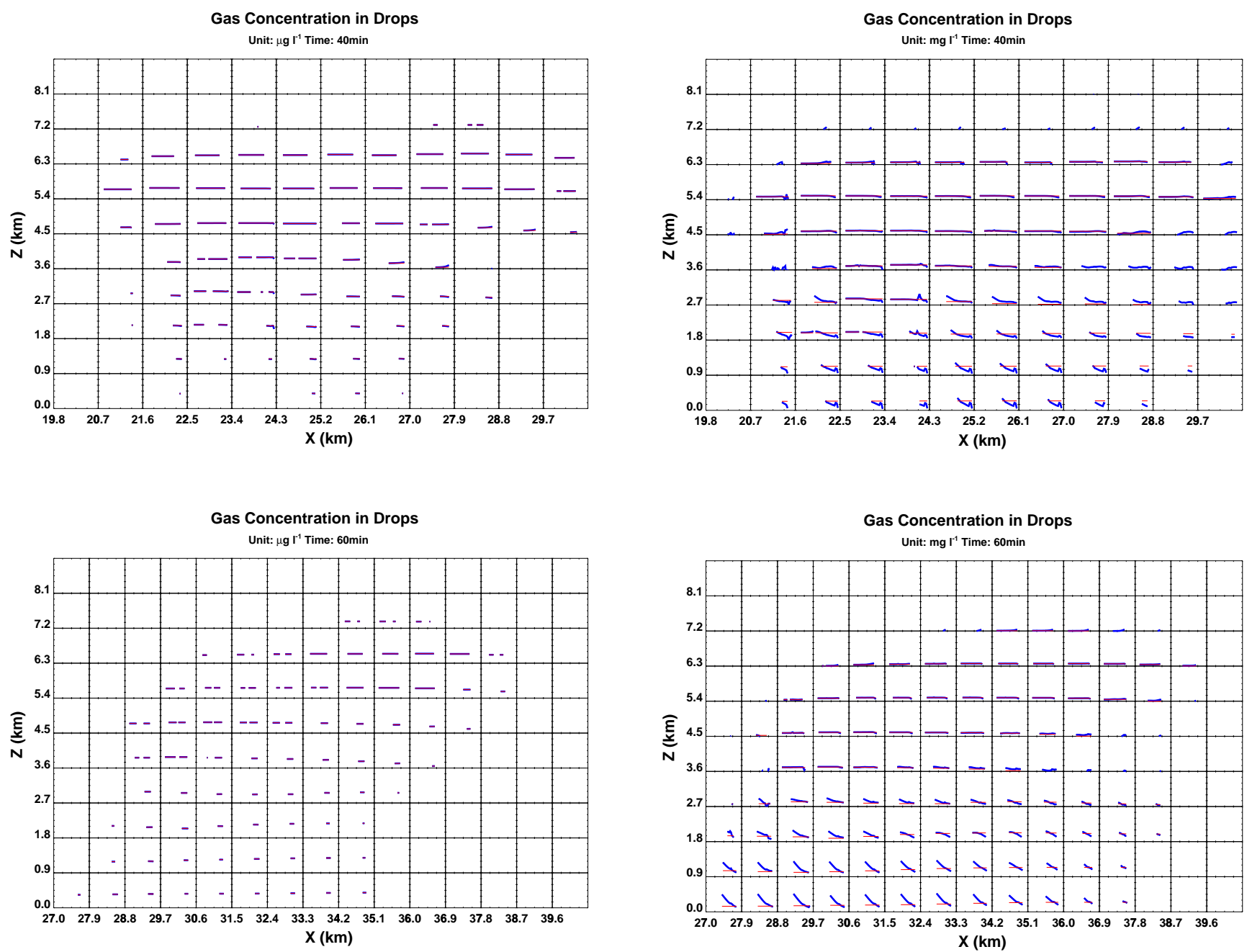

Fig. 9. Distributions of dissolved gas concentration inside drops at different locations after 40 and $60 \mathrm{~min}$ of simulation for the continental-sheared (blue lines) and continental-equilibrium (red lines) simulations. The solubility of the gas is equal to $10^{2} \mathrm{~mol}$ $\mathrm{dm}^{-3} \mathrm{~atm}^{-1}$. In one box the tick values for the abscissa are 1, 10, 1000 , and $10000 \mu \mathrm{m}$, and the range for the ordinate values are from $10^{-2}$ to $10^{4} \mu \mathrm{g} \mathrm{1^{-1 }}$.

clouds and precipitation properties could lead to a big difference in scavenging efficiency.

\subsection{Implications for specific atmospheric gases}

The solubility of trace gases was assumed to be temperatureindependent in the above simulations. Generally, the solubilities of trace gases increase with decreasing temperature. This effect will be particularly important for gases with a high enthalpy of solution, for which the solubility increases most steeply with decreasing temperature (Eq. 10)

To investigate how the results obtained above differ for real gases of interest to atmospheric chemistry, the transport of 20 gases with Henry's law constants ranging from $10^{-3}$ to

Fig. 10. As in Fig. 9 but for $H^{*}=10^{4} \mathrm{~mol} \mathrm{dm}^{-3} \mathrm{~atm}^{-1}$. It should be noted that the unit for the ordinate values in this figure and Fig. 11 is $\mathrm{mg}^{-1}$, different from that in Fig. 9.

more than $10^{10} \mathrm{~mol} \mathrm{dm}{ }^{-3} \mathrm{~atm}^{-1}$ were performed. The results are compared in Fig. 13a and b with those obtained by using temperature-independent Henry's law constants. Each real gas has been placed on the plot at a Henry's law constant value appropriate to that of the gas at $0^{\circ} \mathrm{C}$. The offset from the line indicates the effect on gas transport of including the increasing gas solubility with decreasing temperature. It should be noted that in this simulation we have used the appropriate $0^{\circ} \mathrm{C}$ value of Henry's law constant and enthalpy of solution, but have not included in the model any other effects of these gases, such as altered cloud droplet acidity or chemical reactions. Thus, this simulation represents a realistic natural variation in gas solubility and enthalpy of solution only.

For low solubility gases $\left(H^{*}<10^{3} \mathrm{~mol} \mathrm{dm}^{-3} \mathrm{~atm}^{-1}\right)$ and high solubility gases $\left(H^{*}>10^{6} \mathrm{~mol} \mathrm{dm}^{-3} \mathrm{~atm}^{-1}\right)$ the change of temperature with height has little influence on the 

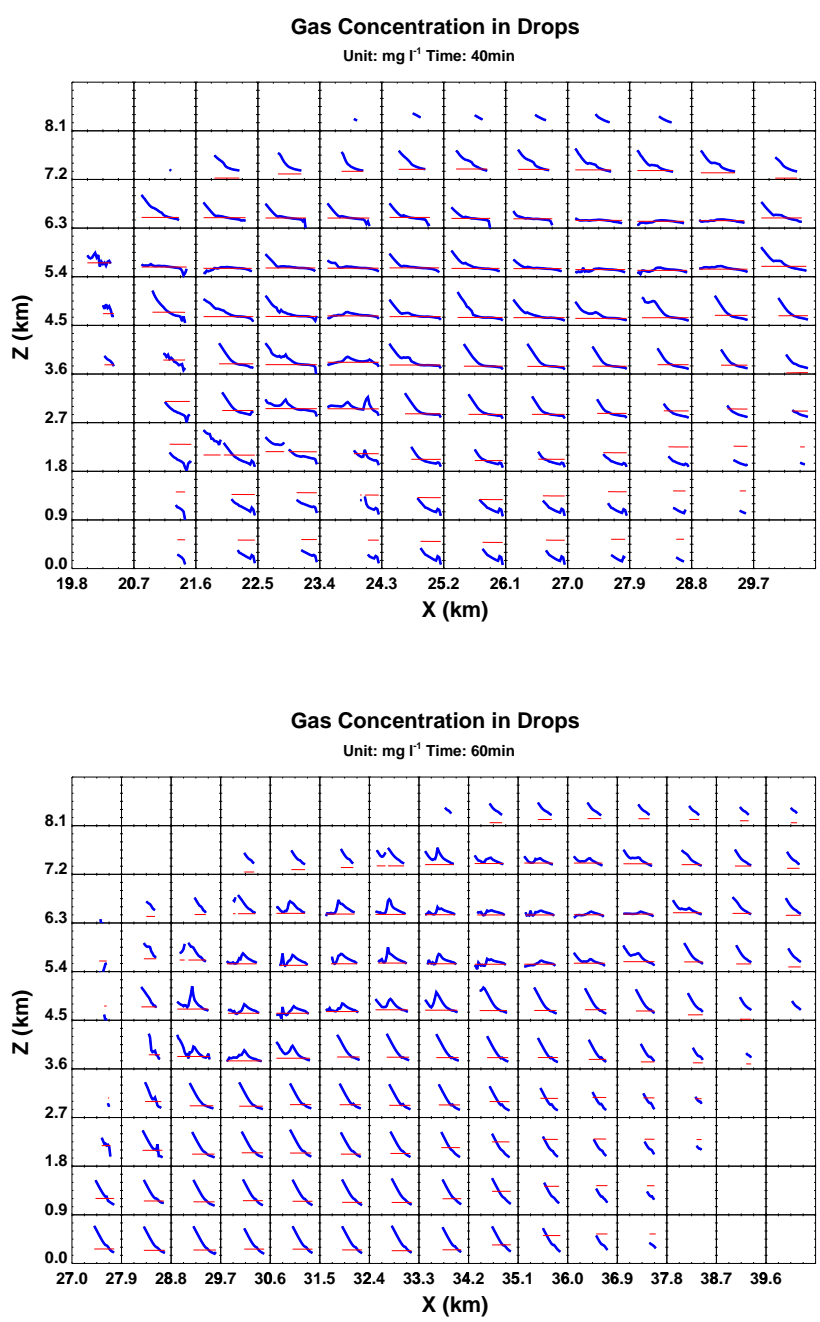

Fig. 11. As Fig. 10 but for $H^{*}=10^{6} \mathrm{~mol} \mathrm{dm}^{-3} \mathrm{~atm}^{-1}$.

gas amount transported, as expected from the previous simulation. However, the transport of gases with moderate solubility $\left(10^{3}<\left(H^{*} / \mathrm{mol} \mathrm{dm}^{-3} \mathrm{~atm}^{-1}\right)<10^{6}\right)$ is significantly different. For example, for $\mathrm{CH}_{3} \mathrm{C}(\mathrm{O}) \mathrm{OOH}$ (peroxyacetic acid), whose solubility increases by a factor of 28 between $25^{\circ} \mathrm{C}$ and $-25^{\circ} \mathrm{C}$, the abundance at cloud top is reduced by $40 \%$ by including the temperature dependence of solubility. The magnitude of the effect depends on the solubility of the gas (high and low solubility gases being hardly affected) and the enthalpy of solution. To further illustrate how the effect varies with enthalpy for moderately soluble gases, we have run the model with a suite of tracers with solubilities ranging from $10^{3}$ to $10^{6} \mathrm{~mol} \mathrm{dm}^{-3} \mathrm{~atm}^{-1}$ and values of $-\frac{\Delta H}{R}$ ranging from zero (no temperature-dependence) to 5000. The values of the integrated species mass above $4 \mathrm{~km}$ and near cloud top level are given in Tables 5 and 6, respectively, varying with both solubility (at a reference temperature $0^{\circ} \mathrm{C}$ ) and the enthalpy. It is clear that the effect by assuming temperatureindependence increases with increasing enthalpy.
The model parameterization of gas transport through clouds used by Crutzen and Lawrence (2000) assumes that the gases have temperature-independent Henry's law constants. If this assumption is made then corrections to the mass transport calculation may have to be included for moderately soluble gases. One possible crude way of including temperature-dependent Henry's law constants would be to artificially increase the temperature-independent value used, based on results from model simulations like ours. From Fig. 13b, the effective (temperature-independent) $0^{\circ} \mathrm{C}$ Henry's law constant of $\mathrm{CH}_{3} \mathrm{C}(\mathrm{O}) \mathrm{OOH}$ would have to be about 7 times higher in order to produce the same lower abundance at cloud top. The gas transport for the real gases seen in Fig. 13 has also been plotted against Henry's law constant at temperatures of $-10,-20,-30^{\circ} \mathrm{C}$ (not shown) from which it can be concluded that there is no single choice of effective cloud temperature which would collapse the data onto the temperature-independent curve.

\subsection{Different trace gas vertical profiles}

So far, we have examined transport from the boundary layer to the free and upper troposphere under the assumption that the gas was originally confined entirely to the boundary layer. Most pollution has its source in the Earth's boundary layer. However, persistent vertical mixing, either by clouds or general eddy diffusion, usually leads to a vertical profile of pollutant concentration that has a maximum in the boundary layer and progressively lower concentrations with increasing altitude. Thus, it is important to understand the relative contribution of different altitude levels to the net change in the abundance of a particular species at cloud top.

We have examined the transport from different altitude layers in a generalized way by flagging a particular gas with the altitude level at which it originated. The different tracers are then examined at each level to gain a picture of the distribution of source altitudes for a particular gas.

Figure 14 summarizes the results of these simulations as contours of gas mass against altitude and source altitude. For a particular altitude in the model domain, the amount of gas contributed to that layer from another altitude layer in the model can be read-off. The gas amounts have been averaged over the full model domain, which is shown in its entirety in Fig. 3, and the gas mixing ratio was assumed to be constant with altitude. Because gas partitioning into the liquid phase depends only on the intensive property $H^{*}$, the results in Fig. 3 can be scaled with any vertical gas concentration profile (if the abundance of a gas at a particular source altitude is increased by a factor $x$, then the contribution of this source altitude to the gas abundance at all other levels will also be increased by a factor $x$.)

The results indicate that the greatest contribution to the abundance of a gas at a particular level is from close to that level itself (the diagonal of high values). This result is true of both insoluble (Fig. 14a) and soluble (Fig. 14b) gases. Also 

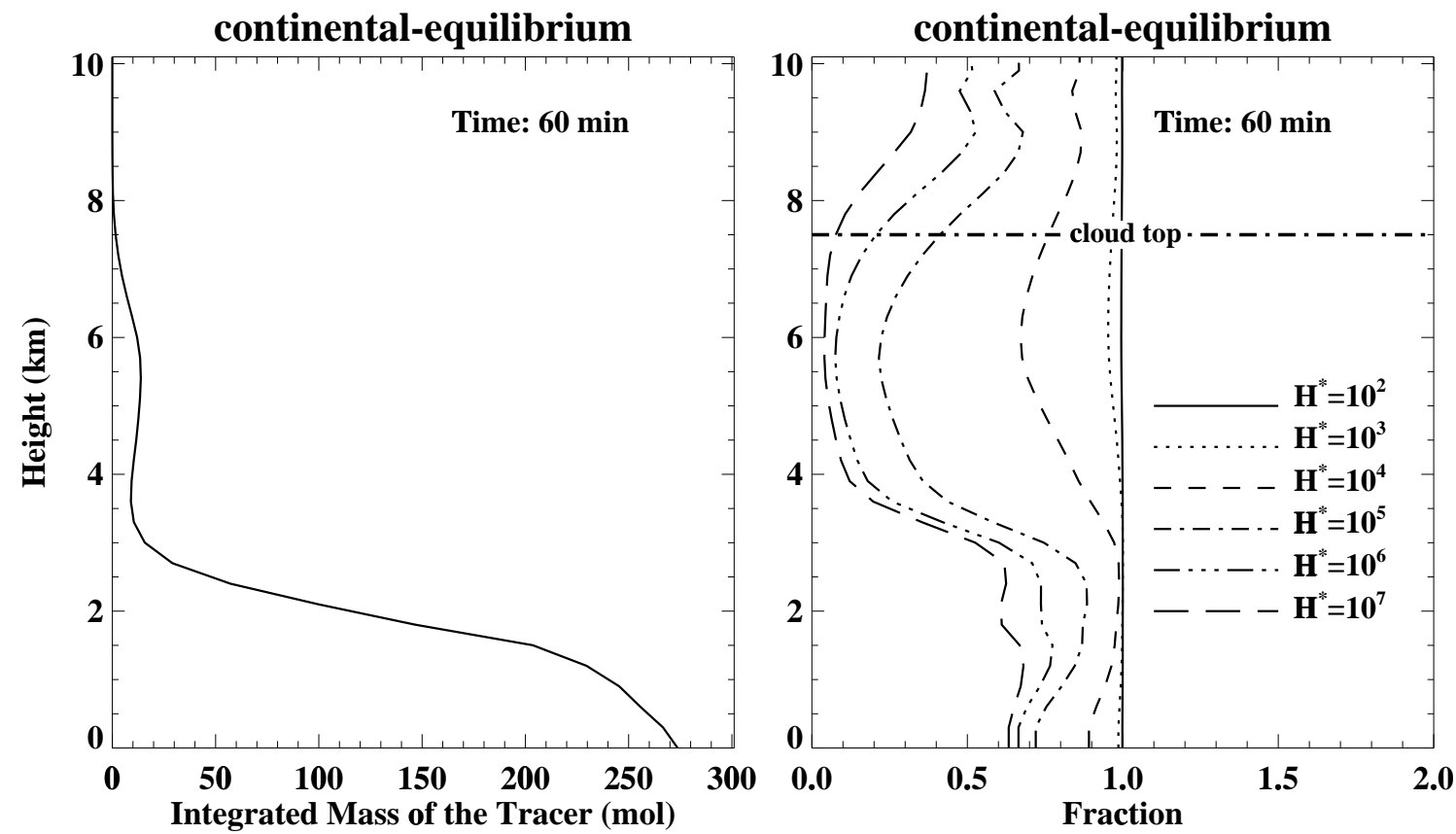

Fig. 12. Similar to Fig. 6 but for the continental-equilibrium simulation in which the gases and droplets are assumed to be in Henry's law equilibrium.
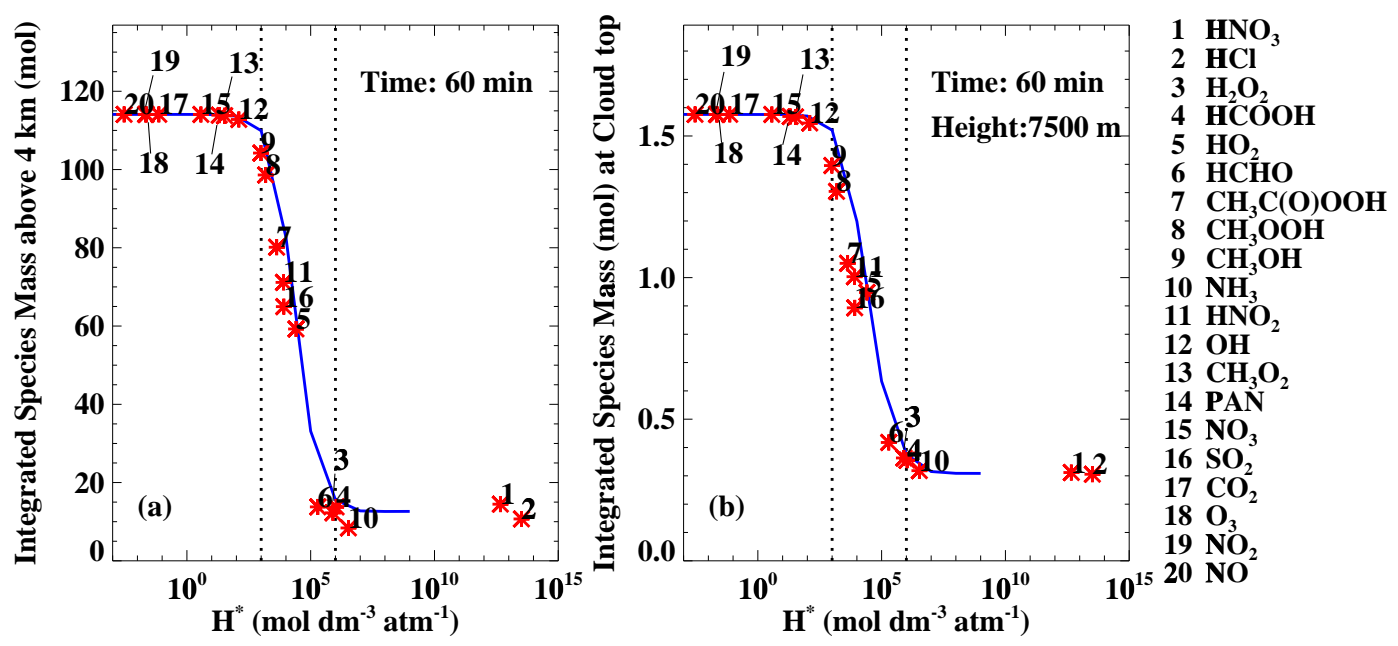

Fig. 13. The effect of the temperature dependence of the Henry's law constant on (a) integrated species mass above $4 \mathrm{~km}$ (or the main outflow region), (b) integrated species abundance at $7500 \mathrm{~m}$ altitude (or the cloud top layer). The solid lines shows the continental-sheared simulation (with constant $H^{*}$ ) and the symbols are results for the 20 real gases listed on the right (for $p \mathrm{H}=5$ ). Note that these simulations do not account for any chemical reactions that these gases may undergo in the liquid or gas phase and are meant to illustrate only the sensitivity to the temperature dependence of solubility.

apparent is a secondary maximum of insoluble gases at high altitudes and low source altitudes. This maximum indicates that the lowest $1-2 \mathrm{~km}$ above the surface contributes slightly more to the gas abundance at high altitudes than do intermediate levels. For example, about $11 \%$ of the insoluble gas at $6 \mathrm{~km}$ comes from the lowest $2 \mathrm{~km}$ of the atmosphere, while $8 \%$ comes from layers between 3 and $5 \mathrm{~km}$. Nevertheless, these simulations show that entrainment of gas from the free troposphere and transport to cloud top is almost as efficient as the direct inflow of air from the boundary layer. At lower altitudes, a significant proportion of the gas has come from higher levels, which results from downdrafts as well as evaporation of precipitation particles for soluble gases.

The contributions of different altitude layers to the total abundance of the gas towards cloud top can be scaled directly in terms of the altitude profile of a particular gas. In 

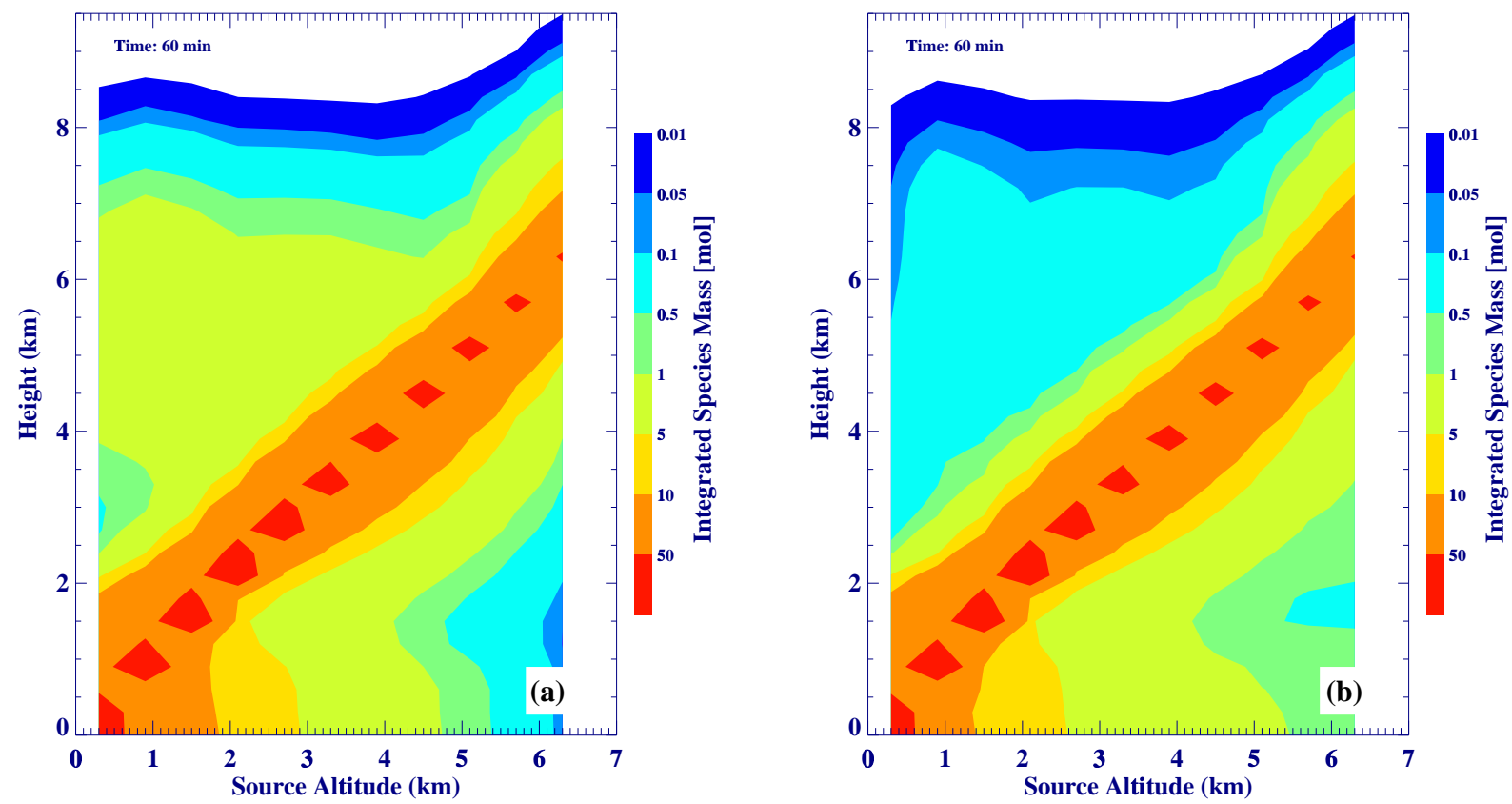

Fig. 14. Contribution of different source altitudes to the abundance of gas at different altitudes in the model domain. (a) An insoluble tracer, (b) a soluble gas with effective Henry's law constant $H^{*}=10^{7} \mathrm{~mol} \mathrm{dm}^{-3} \mathrm{~atm}^{-1}$.

the case of an insoluble gas with the same mixing ratio at all altitudes, these simulations show that approximately $80 \%$ of the gas at $6 \mathrm{~km}$ originated from $\pm 1 \mathrm{~km}$ of that altitude, while only $11 \%$ came from the lowest $2 \mathrm{~km}$ of the atmosphere. Thus, if the abundance of the gas is 8 times greater in the boundary layer than at $6 \mathrm{~km}$ altitude, then a single such cloud event would approximately double the gas abundance at $6 \mathrm{~km}$. With a soluble gas, the contribution from the lowest $2 \mathrm{~km}$ to the abundance at $6 \mathrm{~km}$ is only $\sim 1 \%$. A much steeper fall off in the abundance of such a gas with altitude would be necessary for cloud transport to have a significant effect. It should also be remembered that the cloud we have simulated fills approximately one-third of the 2-D domain, or one-ninth of the equivalent 3-D domain. Larger clouds or several cloud events within the same domain would have a correspondingly greater impact on gas abundances in the free and upper troposphere.

\section{Summary and conclusions}

A two-dimensional cloud model with detailed microphysics has been extended to include trace gas scavenging process, and was used to investigate the sensitivity of trace gas redistribution by convective clouds to cloud macro- and microstructure, gas solubility, and the method of calculating gas uptake into droplets. The emphasis of this study was on developing a general picture of the factors that control gas transport in clouds, rather than focusing on particular gases or case studies.
We have simulated both marine and continental precipitating clouds with a top at approximately $7.5 \mathrm{~km}$, without ice formation. Under these conditions the simulations reveal a clear pattern of behaviour depending on gas solubility. The transport of low solubility gases (with an effective Henry's law constant $H^{*}<10^{3} \mathrm{~mol} \mathrm{dm}{ }^{-3} \mathrm{~atm}^{-1}$ ) was found to be nearly identical to that of an insoluble tracer. All highly soluble gases $\left(H^{*}>10^{6} \mathrm{~mol} \mathrm{dm}^{-3} \mathrm{~atm}^{-1}\right)$ were also found to behave in a nearly identical way, independent of their solubility. The transport of moderately soluble gases $\left(H^{*}\right.$ between $10^{3}$ and $10^{6} \mathrm{~mol} \mathrm{dm}^{-3} \mathrm{~atm}^{-1}$ ) depends on the precise value of $H^{*}$.

The abundance of highly soluble gases was typically less than $0.5 \%$ that of the insoluble tracer in the middle of the cloud, where wet removal processes are dominant. However, in the uppermost parts of the cloud, defined to be approximately the top $1 \mathrm{~km}$ of visible cloud, the abundance of even the most soluble gases was $20-50 \%$ that of the insoluble tracer. This ratio of the abundance of highly soluble gases to that of the insoluble tracer in the uppermost part of the cloud is a parameter that depends on the cloud morphology and microphysics, but is independent of the precise value of Henry's law constant of the soluble gas. Although the abundance of even the insoluble tracer at these altitudes was typically less than $5 \%$ of the boundary layer concentration, the comparatively high concentrations of highly soluble gases at cloud top may not be negligible for some local chemical and aerosol processes.

The abundance of highly soluble gases was found to be 
a factor of 6 higher at the top of continental clouds than in maritime clouds. This much higher abundance is caused by the less efficient wet removal processes in continental clouds. However, the factor of 6 difference in abundance is much greater than the difference in maximum rainfall, which was a factor of 2 greater in the maritime cloud.

Our calculations demonstrate that general statements about the efficiency of gas transport cannot be made, implying that, in large scale models, care must be taken to define the gas solubility, the type of convective cloud involved (i.e. maritime or continental), as well as the altitude of interest.

We have found that the temperature dependence of the Henry's law constant is important for moderately soluble gases and needs to be included in large scale models. For gases with a high enthalpy of solution, the abundance of the gas in the uppermost part of the cloud is equivalent to that of a gas with an effective temperature-independent Henry's law constant evaluated at $0^{\circ} \mathrm{C}$ a factor of 7 higher. The transport of low and high solubility gases is insensitive to the change in solubility with temperature.

A fully kinetic calculation of gas dissolution into the cloud droplets appears to be necessary for an accurate simulation of soluble gas redistribution. Gases with a solubility less than $10^{3} \mathrm{~mol} \mathrm{dm}^{-3} \mathrm{~atm}^{-1}$ are in Henry's law equilibrium with all droplets, while tracers with a solubility between $10^{3}$ and $10^{5} \mathrm{~mol} \mathrm{dm}^{-3} \mathrm{~atm}^{-1}$ are in Henry's law equilibrium for cloud drops but not for rain drops. Gases with even higher solubilities are not in Henry's law equilibrium at all. The assumption of Henry's law equilibrium leads to a factor 5 underestimate of soluble gas abundances in the uppermost parts of the cloud, although the concentrations of all gases are low at such high altitudes.

Acknowledgements. This work was funded by the U.K. Natural Environment Research Council as part of the Upper TroposphereLower Stratosphere (UTLS-Ozone) thematic programme under grant GST/02/2433.

We are grateful to Rolf Sander, Mark G. Lawrence and Mary Barth for their comments and suggestions which helped us to clarify some important points and improved the quality of this paper.

\section{References}

Barth, M. C., Stuart, A. L., and Skamarock, W. C.: Numerical simulations of the July 10 Stratospheric-Tropospheric Experiment: Radiation, Aerosols, and Ozone/Deep Convection storm: Redistribution of soluble tracers, J. Geophys. Res., 106, 12, 381-12, 400, 2001.

Becker, K. H., Kleffmann, J., Kurtenbach, R., and Wiesen, P.: Solubility of nitrous acid (HONO) in sulfuric acid solutions, J. Phys. Chem., 100, 14, 984-14, 990, 1996.

Betterton, E. A. and Hoffmann, M. R.: Henry's law constants of some environmentally important aldehydes, Environ. Sci. technol.,22, 1415-1418, 1988 .
Chatfield, R. B. and Crutzen, P. J.: Sulfur dioxide in the remote oceanic air: Cloud transport of reactive precursors, J. Geophys. Res., 89, 7111-7132, 1984.

Chen, J. P.: Numerical simulation of the redistribution of atmospheric trace chemicals through cloud processes. Ph. D. Thesis. The Pennsylvania State University, University Park, PA 16802, 342 pp, 1992.

Ching, J. K. S. and Alkezweeny, A. J.: Tracer study of vertical exchange by cumulus clouds, J. Clim. Appl. Meteorol., 25, 17021711, 1986.

Clegg, S. L. and Brimblecombe, P.: Solubility of ammonia in pure aqueous and multicomponent solutions, J. Phys. Chem., 93, 7237-7238, 1989.

Cooper, W. A., Bruintjes, R. T., and Mather, G. K.: Some calculations pertaining to hygroscopic seeding with flares, J. Appl. Meteor., 26, 1449-1469, 1997.

Cotton, W. R., Alexander, G. D., Hertenstein, R., Walko, R. L., McAnelly, R. L., and Nicholls, M.: Cloud venting-A review and some new global annual estimates, Earth Sci. Rev., 39, 169-206, 1995.

Crutzen, P. J. and Lawrence, M. G.: The impact of precipitation scavenging on the transport of trace gases: A 3-dimensional model sensitivity study, J. Atmos. Chem., 37, 81-112, 2000.

Dean, J. A.: Lange's Handbook of chemistry, McGraw-Hill, Inc., 1992.

Drummond, J. W., Ehhalt, D. H., and Volz, A.: Measurements of nitric oxide between $0-12 \mathrm{~km}$ altitude and $67^{\circ} \mathrm{N}$ to $60^{\circ} \mathrm{S}$ latitude obtained during STRATOZ III, J. Geophys. Res., 93, 15, 831$15849,1988$.

Ehhalt, D. H., Rudolph, J., Meixner, F., and Schmidt, U.: Measurements of selected $\mathrm{C}_{2}-\mathrm{C}_{5}$ hydrocarbons in the background troposphere: Vertical and latitudinal variations, J. Atmos. Chem., 3, 29-52, 1985.

Flossmann, A. I. and Wobrock, W.: Venting of gases by convective clouds, J. Geophys. Res., 101, 18 639-18 649, 1996.

Gardner, J. A., Watson, L. R., Adewuyi, Y. G., Davidovits, P., Zahniser, M. S., Worsnop, D. R., and Kolb, C. E.: Measurement of the mass accommodation coefficient of $\mathrm{SO}_{2}(\mathrm{~g})$ on water droplets, J. Geophys. Res., 92, 10, 887-10, 895, 1987.

Hoffmann, M. R. and Calvert, J. G.: Chemical transformation models for Eulerian acid deposition models, vol. 2. The aqueous-phase chemistry, Rep. EPA/600/3-85/017, Environ. Prot. Agency, Research Triangle Park, N. C., 1985.

Johnson, B. J., Betterton, E. A., and Craig, D.: Henry's law coefficients of formic and acetic acids, J. Atmos. Chem., 24, 113-119, 1996.

Jacob, D. J.: Chemistry of $\mathrm{OH}$ in remote clouds and its role in the production of formic acid and peroxymonosulfate, J. Geophys. Res., 91, 9807-9826, 1986.

Kames, J., Schweighoefer, S., and Schurath, U.: Henry's law constant and hydrolysis of peroxyacetyl nitrate (PAN), J. Atmos. Chem., 12, 169-180, 1991.

Klaning, U. K., Sehested, K., and Holcman, J.: Standard Gibbs free energy of formation of hydrxyl radical in aqueous solution; Rate constants for the reaction $\mathrm{ClO}_{2}^{-}+\mathrm{O}_{3} \rightleftharpoons \mathrm{O}_{3}^{-}+\mathrm{ClO}_{2}$. J. Phys. Chem., 89, 760-763, 1985.

Kreidenweis, S. M., Zhang, Y., and Taylor, G. R.: The effects of clouds on aerosol and chemical species production and distribution 2. Chemistry model description and sensitivity analysis, J. 
Geophys. Res., 102, 23 867-23 882, 1997.

Le Henaff, P.: Methods d'etude et proprietes des hydrates, hemiacetals et hemiacetals derives des aldehydes et des cetones, Bull., Soc. Chem. France, 4687-4700, 1968.

Lide, D. R. and Frederikse, H. P. R., editors: CRC Handbook of Chemistry and Physics, 76 Edition, CRC Press, Inc., Boca Raton, FL., 1995.

Mari, C., Jacob, D. J., and Bechtold, P.: Transport and scavenging of soluble gases in a deep convective cloud, J. Geophys. Res., 105, 22 255-22 267, 2000.

Marsh, A. R. W. and McElroy, W. J.: The dissociation constant and Henry's law constant of $\mathrm{HCl}$ in aqueous solution, Atmos. Environ., 19, 1075-1080, 1985.

Martell, A. E. and Smith, R. M.: Critical Stability Constants, vol. 3, Other Organic Ligands, Plenum, New York, 1977.

Mozurkewich, M., Mcmurry, P. H., Gupta, A., and Calvert, J. G.: Mass accommodation coefficient for $\mathrm{HO}_{2}$ radicals on aqueous particles, J. Geophys. Res., 92, 4163-4170, 1987.

Murphy, D. M., Thomson, D. S., and Mahoney, T. M. J.: Insitu measurements of organics, meteoritic material, mercury, and other elements in aerosols at 5 to 19 kilometers, Science, 282, 1664-1669, 1998.

O'sullivan, D. W., Lee, M., Noone, B. C., and Heikes, B. G.: Henry's law constant determinations for hydrogen peroxide, methyl hydroperoxide, hydroxymethyl hydroperoxide, ethyl hydroperoxide, and peroxyacetic acid, J. Phys. Chem., 100, 32413247, 1996.

Pandis, S., and Seinfeld, J. H.: Sensitivity analysis of a chemical mechanism for aqueous-phase atmospheric chemistry, J. Geophys. Res.,94, 1105-1126, 1989.

Perrin, D. D.: Ionization Constants of Inorganic Acids and Bases in Aqueous Solution, 2nd ed., Pergamon, New York, 1982.

Pickering, K. E., Dickerson, R. R., Luke, W. T., and Nunnermacker, L. J.: Clear-sky vertical profiles of trace gases as influenced by upstream convective activity, J. Geophys. Res., 94, 14, 879-14, 892,1989

Pruppacher, H. R., and Klett, J. D.: Microphysics of Clouds and Precipitation. D. Reidel, 714pp, 1997.

Régimbal, J.-M. and Mozurkewich, M.: Peroxynitric acid decay mechanisms and kinetics at low $p \mathrm{H}$, J. Phys. Chem. A, 101, 8822-8829, 1997.

Sander, R.: Compilation of Henry's law constants for inorganic and organic species of potential importance in environmental chemistry (version 3), http://www.mpchmainz.mpg.de/ sander/res/henry.html, 1999.
Saxena, P. and Hildemann, L. M.: Water-soluble organics in atmospheric particles: A critical review of the literature and application of thermodynamics to identify candidate compounds, J. Atmos. Chem., 24, 57-109, 1996.

Schwartz, S. E. and White, W. H.: Solubility equilibria of the nitrogen oxides and oxyacids in dilute aqueous solution, In Pfafflin, J. R. and Ziegler, E. N., editors: Advances in Environmental Science and Engineering, vol. 4, p. 1-45. Gordon and Breach Science Publishers, NY, 1981.

Seinfeld, J. H. and Pandis, S.: Atmospheric Chemistry and Physics: From air pollution to climate change, 1326, John Wiley \& Sons, Inc., New York, 1998.

Smith, R. M. and Martell, A. E.: Critical Stability Constants. Vol. 4: Inorganic Complexes, Plenum Press, New York, 1976.

Snider, J. R. and Dawson, G. A.: Tropospheric light alcohols, carbonyls, and acetonitrile: Concentrations in the southwestern United States and Henry's law data, J. Geophys. Res., 90D, 3797-3805, 1985.

Takeda, T.: Numerical simulation of a precipitating convective cloud: The formation of a "Long-Lasting" cloud, J. Atmos. Sci., 28, 350-376, 1971.

Thomas, K., Volz-Thomas, A., Mihelcic, D., Smit, H. G. J., and Kley, D.: On the exchange of $\mathrm{NO}_{3}$ radicals with aqueous solutions: Solubility and sticking coefficient, J. Atmos. Chem., 29, 17-43, 1998.

Tremblay, A.: Cumulus cloud transport, scavenging and chemistry - observations and simulations, Atmos. Environ., 21, 23452364, 1987.

Twomey, S. and Wojciechowski, T. A.: Observations of the geographical variation of cloud nuclei, J. Atmos. Sci., 26, 684-688, 1969.

Tzivion, S., Feingold, G., and Levin, Z.: A efficient numerical solution to the stochastic collection equation, J. Atmos. Sci., 44, 3139-3149, 1987.

Wang, C. and Chang, J. S.: A three-dimensional numerical model of cloud dynamics, microphysics, and chemistry, 3. redistribution of pollutants. J. Geophys. Res., 98, 16, 787-16, 798, 1993.

Wang, C. and Crutzen, P. J.: Impact of a simulated severe local storm on the redistribution of sulfur dioxide, J. Geophys. Res., 100, 11, 357-11367, 1995.

Yin, Y., Levin, Z., Reisin, T. G., and Tzivion, S.: The effects of giant cloud condensation nuclei on the development of precipitation in convective clouds - A numerical study, Atmos. Res., 53, 91116, 2000. 